NBER WORKING PAPER SERIES

NUDGING ENERGY EFFICIENCY BEHAVIOR:

THE ROLE OF INFORMATION LABELS

\author{
Richard G. Newell \\ Juha V. Siikamäki \\ Working Paper 19224 \\ http://www.nber.org/papers/w19224
NATIONAL BUREAU OF ECONOMIC RESEARCH
1050 Massachusetts Avenue
Cambridge, MA 02138 \\ July 2013
}

For comments on a previous version of the paper we thank Kenneth Gillingham and seminar participants at the 2013 AEA annual conference, the 2012 AERE annual conference, the 2012 D-CIDES Conference on Decision Making across the Disciplines at Duke University, and the EPA-NCEE workshop on Benefits of Environmental Information Disclosure. We also thank the U.S. Environmental Protection Agency for funding under a STAR grant. The views expressed herein are those of the authors and do not necessarily reflect the views of the National Bureau of Economic Research.

NBER working papers are circulated for discussion and comment purposes. They have not been peerreviewed or been subject to the review by the NBER Board of Directors that accompanies official NBER publications.

(C) 2013 by Richard G. Newell and Juha V. Siikamäki. All rights reserved. Short sections of text, not to exceed two paragraphs, may be quoted without explicit permission provided that full credit, including (C) notice, is given to the source. 
Nudging Energy Efficiency Behavior: The Role of Information Labels

Richard G. Newell and Juha V. Siikamäki

NBER Working Paper No. 19224

July 2013

JEL No. C91,D12,D83,D91,H43,Q41,Q48

\begin{abstract}
$\underline{\text { ABSTRACT }}$
We evaluate the effectiveness of energy efficiency labeling in guiding household decisions. Using a carefully designed choice experiment with alternative labels, we disentangle the relative importance of different types of information and intertemporal behavior (i.e., discounting) in guiding energy efficiency behavior. We find that simple information on the economic value of saving energy was the most important element guiding more cost-efficient investments in energy efficiency, with information on physical energy use and carbon emissions having additional but lesser importance. The degree to which the current EnergyGuide label guided cost-efficient decisions depends importantly on the discount rate assumed. Using individual discount rates separately elicited in our study, we find that the current EnergyGuide label came very close to guiding cost-efficient decisions, on average. However, using a uniform five percent discount rate - which was much lower than the average elicited rate - the EnergyGuide label led to choices that result in a one-third undervaluation of energy efficiency. We find that labels that also endorsed a model (with Energy Star) or gave a suggestive grade to a model (EU-style label), encouraged substantially higher energy efficiency. Our results reinforce the centrality of views on intertemporal choice and discounting, both in terms of understanding individual behavior and in guiding policy.
\end{abstract}

\author{
Richard G. Newell \\ Nicholas School of the Environment \\ Duke University \\ Box 90227 \\ Durham, NC 27708 \\ and NBER \\ richard.newell@duke.edu \\ Juha V. Siikamäki \\ Resources for the Future \\ 1616 P St NW \\ Washington DC 20036-1400 \\ juha@rff.org
}




\title{
Nudging Energy Efficiency Behavior: The Role of Information Labels
}

\author{
Richard G. Newell and Juha Siikamäki*
}

\section{Introduction}

Many information programs are in place to guide energy consumption decisions by firms and households, including product labeling, energy audits, voluntary public-private partnerships, mailings, internet-based information, and other methods. Notwithstanding their differences, these programs all intend to improve energy efficiency choices by firms and households. With limited or otherwise imperfect information about the potential benefits and costs of energy-efficient choices, households may not be eager to opt for products that are more energy efficient but also more costly at the time of purchase. Information programs seek to address impediments to economically efficient consumer and firm decisionmaking by providing understandable information and assisting in the weighing energy cost savings against higher capital cost.

Despite the central role that information programs play in existing and proposed energy efficiency policy portfolios, surprisingly little is known about how consumers and firms respond to such programs. Although a reasonably large literature surveys various potential market failures in energy efficiency investment, ${ }^{1}$ few analyses have focused specifically on information programs, partly because of inadequate data. Energy efficiency labeling is a particularly prominent program in this context. For example, the major household appliances sold in the United States must include the EnergyGuide label to describe their estimated annual energy usage and operation costs. Similar energy efficiency labeling programs, often with alternative label formats, are widely used worldwide. Moreover, in some cases, multiple differently

\footnotetext{
*Newell is the Gendell Professor of Energy and Environmental Economics, Duke University; director of the Duke University Energy Initiative; and a research associate at the National Bureau of Economic Research (richard.newell@duke.edu). Siikamäki is associate research director and fellow at Resources for the Future (juha@rff.org). For comments on a previous version of the paper we thank Kenneth Gillingham and seminar participants at the 2013 AEA annual conference, the 2012 AERE annual conference, the $2012 \mathrm{D}-\mathrm{CIDES}$ Conference on Decision Making across the Disciplines at Duke University, and the EPA-NCEE workshop on Benefits of Environmental Information Disclosure. We also thank the U.S. Environmental Protection Agency for funding under a STAR grant.

${ }^{1}$ See, for example, Ruderman et al. (1987), Sutherland (1991), Metcalf(1994), Jaffe and Stavins (1994), Gillingham et al. (2006, 2009), Tietenberg (2009), Allcott and Greenstone (2012), and Gillingham and Palmer (2013).
} 
structured information programs, such as EnergyGuide and Energy Star in the United States, address the energy usage of the same appliance.

As noted by Allcott and Greenstone (2012), however, no large-scale evaluations are available on the impact of energy efficiency labeling on consumer choices. This is the focus of our study. We use an experimental approach to evaluate the effectiveness of information provision through labeling in improving energy efficiency decisions by households. By coupling a carefully designed choice experiment with information on all of the key elements of intertemporal energy efficiency choices, we are able to disentangle the role played by (a) different types of information and (b) intertemporal behavior (i.e., discounting) in guiding energy efficiency behavior.

Earlier work has focused on the role of information in energy efficiency decisions by firms. ${ }^{2}$ More recently, several studies have investigated the role of inadequate and asymmetric information, inattention, and other behavioral drivers of the adoption of energy-efficient appliances and technologies by households. For example, Davis (2010) examines the difference between rental units and owner-occupied homes and finds that renters are 1 to 10 percentage points less likely to have Energy Star appliances. Similarly, Gillingham et al. (2012) find that owner-occupied houses in California are 12 to 20 percent more likely to have insulation than rental units. Both studies estimate the findings conditional on potentially confounding and observable characteristics of the property, occupant, and neighborhood.

In research regarding vehicle fuel efficiency, Allcott (2011a) finds that consumers are poorly informed about the financial value of fuel efficiency, typically substantially misestimating the gasoline cost difference between the vehicle they own and other potentially preferred vehicles. However, the misestimate is not systematically greater than the actual value. One way to better inform decisions is to use information disclosure programs, such as energy efficiency

\footnotetext{
2 DeCanio and Watkins (1998) investigate voluntary participation in the US Environmental Protection Agency's Green Lights Program, finding that the characteristics of individual firms influence their decision to participate in the program. Morgenstern and Al-Jurf (1999) find that information provided through demand-side management utility programs appears to make a significant contribution to the diffusion of high-efficiency lighting in commercial buildings. Newell et al. (1999) find that the responsiveness of energy-efficient innovation in home appliances to energy price changes increased substantially after energy efficiency product labeling was required. Anderson and Newell (2004) analyze technology adoption decisions of manufacturers in response to free energy audits. They find that plants respond as expected to financial costs and benefits, though there are unmeasured project-related factors that also influence investment decisions. Revealed behavior of plants suggests that most require a payback period of 15 months or less as their investment threshold.
} 
labels. Other studies have used structured interviews (Turrentine and Kurani 2007) or laboratory studies (Larrick and Sol 2008) to assess the role of imperfect information in automobile fuel economy decisions, finding that consumers are not very adept at the calculations underlying costeffective decisions. Larrick and Sol (2008) further find that the form of information provision in labels could guide people in incorrect directions depending on how they process that information.

Sallee (2012) develops a heuristic model of consumer energy efficiency decisionmaking, in which uncertainty about goods' energy efficiency can be resolved through a costly search. The paper argues that energy consumption labels are not sufficient to eliminate this uncertainty; that rational inattention may therefore play an important role; and that if consumers are inattentive, then providing salient signals, such as a binary energy efficiency certification (e.g., the Energy Star logo) may be efficient, even if it induces supply distortions. In a welfare evaluation of the Energy Star program, Houde (2011) suggests that the program may improve social welfare and lead to large energy savings. He finds that, under certain circumstances, certification may induce consumers to invest too much in energy efficiency; however, the certification also partly crowds out efforts to fully account for energy costs, and may therefore induce consumers to invest too little in energy efficiency.

Another important aspect of this type of investment decisionmaking is the hurdle rate or other discounting factor that consumers employ when measuring current costs against future benefits. A substantial literature suggests that "implicit discount rates," which one can calculate based on the capital cost versus energy operating cost savings of alternative projects, can be quite high in practice (Hausman 1979; Train 1985). As noted above, a related literature further contends that these high implicit discount rates are attributable to various market barriers and failures - including information problems — and that these problems can be ameliorated by appropriate policies. However, the literature has been hampered by an inability to disentangle individual intertemporal preferences from market failure explanations for energy efficiency decisions. We approach this issue by separately eliciting data on individual discount rates so that their role as part of the energy efficiency decision can be assessed, as explained in section 2 below.

\section{Overview of Approach}

Our purpose in this study is, first, to experimentally examine the extent to which any reluctance of households to adopt energy-efficient appliances stems from informational inefficiencies and, second, to identify the degree to which these inefficiencies can be resolved by 
alternative information disclosure programs, such as different forms of energy efficiency labeling. We are interested not only in the current US product-labeling options, such as EnergyGuide and Energy Star, but also in their potential variations. We focus on investigating potential misperceptions by consumers and households - that is, the extent to which their decisions diverge from an objectively determined optimal behavioral principle. Exploring energy efficiency in this regard is especially attractive because a clearly measurable value can be attached to the averting behavior (i.e., the direct value of the energy savings), and a relatively objective measure is available of what might constitute a "best choice," based on minimization of present value costs under a particular discount rate.

We examined the above issues by conducting a series of stated choice experiments, in which a large number of randomly selected US homeowners were subject to randomized treatments using alternative energy efficiency labeling programs. Each study participant went through several product choice decisions, which involved choosing the preferred option from different available appliance options. We evaluated a large number of different alternative product models across the respondents and each labeling treatment so that the data elicited enabled a statistically efficient estimation of how different product attributes, including the energy efficiency of the appliance, determine households' appliance choice.

Methodologically, the survey draws from (conjoint) choice experiment methods, which are widely used in models of individual decisionmaking (e.g., McFadden 1974; Louviere et al. 2000; Train 2003). The objects of household choice — alternative appliances — are viewed as bundles of product attributes, such as purchase price, energy efficiency, durability, capacity, and brand. Using data on a large number of choices among products with an array of characteristics, statistical analyses can recover implicit preference trade-offs between different attributes, such as energy efficiency and product price, helping to reveal the valuation of each product attribute by the decisionmakers examined.

Although field experiments have an advantage in assessing decisions in an actual rather than hypothetical context, the experimental approach taken here has advantages in terms of the detail and control with which we are able to construct the choice experiment as well as the rich information we have on respondents. Moreover, regardless of the hypothetical context, surveybased approaches are informative in projecting market valuations. For example, in an extensive review of hypothetical and revealed preference studies to value quasi-public goods, Carson et al. (1996) find that the valuations based on hypothetical and revealed preference approaches are similar for similar goods. On average, stated preference studies predict values that are about 90 percent of the estimates derived from revealed preference studies. The extent of commercial 
market research, the main user of the choice experiment method, also demonstrates the value of this method in eliciting information on consumer preferences (Louviere et al. 2000).

To guarantee that our stated preference survey is pertinent to the respondents, we sampled respondents who are the owners of single-family homes and elicited choice data regarding a central household water heater. Studying preferences for a water heater provides a range of advantages to this study. For example, all homes in our sample feature a central water heater, so focusing on it enables the development of a realistic choice situation to which each study participant can potentially be exposed. Moreover, water heaters have a comparatively simple product attribute space, which helps the design of relatively uniform decision problems across a large sample of households. Additionally, water heaters have reasonably high upfront and annual operation costs, which is useful when examining households' valuation of energy efficiency and their willingness to pay (WTP) for it. In addition, the annual operation cost of water heaters is entirely associated with the use of a single type of fuel and not a combination of multiple sources, such as electricity, natural gas, and water use, as may be the case with some other energy-using equipment, such as heating systems or clothes washers.

A household's subjective valuation of energy efficiency is revealed by the investment it is willing to make for increased energy efficiency of the water heater. This involves intertemporal trade-offs between the higher up-front purchase price and longer-term energy operating cost savings. Besides the purchase price and the annual operation cost of the water heater, the value of the long-term energy savings to the household therefore depends on the discount factor and the planning horizon used.

To help better understand the role of discounting in households' valuation of energy efficiency, we separately elicited individual-specific discount rates from each study participant. Using an approach from the experimental economics literature (Coller and Williams 1999), each respondent went through a series of choices for receiving different amounts of money at two different points in time - one (payment A) available one month hence and the other (payment B) available in one year. We used a fixed amount $(\$ 1,000)$ for the payment available in 1 month, and varied the amount available in 12 months. Using multiple payment comparisons for each study participant, we determined the amount received in one year to which the person is indifferent and, based on this amount, inferred an implicit discount rate that equalizes the present value of the two payments.

In the rest of the paper, we first explain the household survey experiments conducted in this study, including their development, design, and implementation. Thereafter, we develop an 
econometric model for directly estimating households' subjective valuation of energy efficiency as an appliance attribute. We then present and discuss our estimation results.

\section{Household Survey Experiments}

\section{Survey Development}

We developed the experiments in four stages. First, we conducted focus groups to better understand how households approach appliance choice decisions, the importance of energy efficiency in those decisions, and the perceptions of households of several alternative energylabeling programs. Each focus group participant also completed a draft of our survey instrument so that we could discuss it. Second, we asked colleagues to complete and review a computerized version of the experiment. Third, we revised and tested five alternative energy-labeling treatments using pilot experiments with our sample of households. These treatments functioned well, and their data therefore comprise part of our overall assessment. Fourth, we finalized the survey instrument and developed and administered further information treatments. Altogether, we examined 12 labeling treatments, described in more detail below.

\section{Survey Sample}

We implemented the experiments using a computerized instrument and a random sample from the GfK panel (formerly the Knowledge Networks panel). The GfK panel is a probabilitybased respondent panel designed to be representative of the United States. ${ }^{3}$ The panel is widely used for academic research in many fields; applications to economics include, for example, Rabin and Weizsacker (2009) and Fong and Luttmer (2009). Our sampling frame consists of homeowners among US residents age 18 and older. Only one person per household could be selected to participate in the experiments. Additionally, the study participant had to be a head of the household, ensuring that the data elicited in the study correspond to preferences of those individuals most likely to make decisions regarding major appliances.

\footnotetext{
3 Panel members are recruited by random digit dialing (RDD) sampling and address-based sampling methodologies. To offset attrition, multiple recruitment samples are fielded evenly throughout the calendar year. GfK panel recruitment methodology has used the quality standards established by selected RDD surveys conducted for the federal government (such as the Centers for Disease Control and Prevention-sponsored National Immunization Survey).
} 
The GfK panel is especially helpful for the purposes of this study not only because it enables sampling from the general population, but also because the basic information about panel members, such as their home ownership, is known in advance. Moreover, the panel enables the use of a computerized and automated survey instrument, which is essential, as we explain later. Finally, GfK panelists are accustomed to occasionally taking surveys, so their level of comfort in going through surveys such as ours is high.

The survey administration consisted of two stages: initial screening to ensure that the respondent considered himself or herself a head of the household, followed by the main survey with study-eligible respondents. Of 2,936 individuals initially contacted, 1,909 (65.0 percent) passed the initial screening. Of those passing the initial screening, 1,248 individuals (65.4 percent) qualified for the survey. These individuals form our survey sample; altogether, 1,217 (97.4 percent) of them completed the experiment (with 1,214 individuals fully completing the choice experiments).

To enhance survey cooperation, we sent email reminders to nonresponders on day three of the field period; additional email reminders to nonresponders were sent throughout the field period; and participants were eligible to win an in-kind prize through a monthly GfK sweepstakes.

Table 1 provides descriptive statistics on the characteristics of the households in our sample. For comparison, we compiled estimates of the household characteristics of US homeowners from American Housing Survey data (US Census Bureau 2012). Although slight differences emerge between our sample vs. that of the American Housing Survey in income $(\$ 65,206$ vs. $\$ 58,919)$ and education level (40 percent vs. 35 percent with a minimum of a bachelor's degree), our sample matches well the average household characteristics of US homeowners.

\section{Energy Label Treatments}

Each study participant was randomly assigned to 1 of the 12 different energy-labeling treatments, each of which included about 100 study participants (i.e., about 1,200 respondents and 12 treatments yields a subsample of about 100 respondents per treatment). Aside from the energy-labeling treatment, the experiments faced by each respondent were identical. That is, different treatments elicited choices about the same appliance options; only the information presented differed. 
We next describe the labeling treatments. The current EnergyGuide label (Figure 1) provides the baseline; most of the treatments are variations of the EnergyGuide label. Our experimental approach involves evaluating both the information content and the style of representing the information on the label. Regarding information content, we evaluated the use of economic information ("estimated yearly operating cost" in the current EnergyGuide label) and physical information on energy use ("estimated yearly energy use" in the current EnergyGuide label) as well as the inclusion or exclusion of the range of energy costs for other similar appliance options on the market ("cost range of similar models" in the current EnergyGuide label). Moreover, we examined whether including information on the environmental consequences of the appliance choice in the form of carbon dioxide $\left(\mathrm{CO}_{2}\right)$ emissions influences study participants' appliance choice decisions.

Regarding the style of representing the information, we examined treatments that included or excluded the current EnergyGuide logo and its colors. We also evaluated an altogether different energy-labeling option: an energy efficiency grade label, which is commonly used in Europe, parts of Asia, and South America. The energy efficiency grade label, illustrated in Figure 2, was identified as one of the favorite labels by the focus group participants, so it was included in the experiments.

Finally, we fielded treatments that included (with and without the EnergyGuide label) the Energy Star logo administered by the US Environmental Protection Agency. The Energy Star logo is approved for display only on high-efficiency product models. These treatments help examine the effectiveness of multiple simultaneous labeling programs with related information content, as is the current policy practice in the United States.

To evaluate the above dimensions of an energy-labeling program, we designed and administered 12 labeling treatments, which fall into the following 4 main categories (examples of the graphics used in the different treatments and a table summarizing the information attributes of the treatments are included in the appendix in Figure A1 and Table A5):

1) current EnergyGuide label and its direct variations

a. current label (information on the yearly operation cost, energy use, and the range of yearly operation cost of similar appliances; Figure A1.1).

b. variations

i. yearly operation cost and range only (Figure A1.2)

ii. yearly energy use only (kilowatt-hours [kWh], therms; Figure A1.3)

iii. simplified EnergyGuide 
1. no EnergyGuide logo or colors (Figure A1.4)

2. no EnergyGuide logo or colors; no range of yearly operation cost of similar appliances (Figure A1.5)

2) Energy Star labels
a. Energy Star with EnergyGuide (Figure A1.6)
b. Energy Star with simplified EnergyGuide (Figure A1.7)
c. Energy Star without EnergyGuide (Figure A1.8)

3) labels with $\mathrm{CO}_{2}$ information

a. EnergyGuide with $\mathrm{CO}_{2}$ information expressed in a manner similar to that of yearly energy usage (numeric data; Figure A1.9)

b. simplified EnergyGuide with $\mathrm{CO}_{2}$ information using graphics (carbon footprint) and numeric information (Figure A1.10)

c. information only on $\mathrm{CO}_{2}$ using graphics (carbon footprint) and numeric information; no EnergyGuide (Figure A1.11)

4) energy efficiency grade, with operating cost (EU-style label, ${ }^{4}$ similar versions are also used in parts of South America, China and other Asian countries, and Russia; Figure A1.12)

In the estimation model, we describe different labeling treatments as a set of common attributes, such as the absence or presence of economic information, physical information, EnergyGuide label graphics, the Energy Star logo, and so forth, as explained below. In addition to helping reduce the dimensionality of the treatments, this enables the construction of compound information treatments to help better understand and evaluate different labeling program options. Nonetheless, we have also estimated the model directly, employing the 12 treatments as separate variables. Those specifications generate results similar to those presented here but are less readily interpretable for contrasting how the different attributes of the label affect households' choices and implicit valuation of energy efficiency.

\section{Choice Experiment Design}

Our choice experiments follow a standard framework used in the marketing, economics, and transportation literature for eliciting data on individual preferences (e.g., Louviere et al. 2000). Each study participant was subjected to five different choice decisions, each of which

\footnotetext{
${ }^{4}$ Note that the actual EU efficiency label does not include operating cost information.
} 
contrasted three water heater alternatives. Different water heater options varied by purchase price and the attributes included in the labeling treatment. In each choice problem, the study participant indicated which of the three options he or she preferred, assuming that they were the only options available and assuming that the water heater replacement was necessary and imminent. A stylized example of the choice problem using the current EnergyGuide labeling treatment is shown in Figure 3. Other labeling treatments replaced the graphics in the "energy use" row with a graphic corresponding to each alternative treatment.

Prior to the choice problems, the survey instrument introduced the study and explained the upcoming choice questions and the information portrayed by the labels. The survey also collected basic information regarding the home of the respondents (for example, the fuel type of the water heater and water heater's capacity and type). The respondents were also asked questions about the importance of many different factors in the potentially sudden decision to replace a water heater. Besides eliciting valuable data, these questions prepared the respondents to carefully consider a potential water heater replacement decision.

When explaining the choice problems, we explained in detail and intuitively the meaning of each appliance attribute. Figure A2 in the appendix illustrates the description of attributes in the current EnergyGuide labeling treatment. ${ }^{5}$ Although water heaters are relatively uniform, some differences among them go beyond the attributes examined here. We therefore asked each study participant to assume that the appliance options presented in the experiments matched in all other respects the desired replacement option for his or her home.

\section{Choice Set Design}

The range of potential energy cost, purchase price, and $\mathrm{CO}_{2}$ emissions of different appliance options are summarized in Table A1 in the appendix. We developed the ranges of all attributes to correspond to the actual range of appliances currently available, as explained below.

\footnotetext{
${ }^{5}$ For the "purchase price" attribute, we noted that it "denotes your out-of-pocket cost of purchasing the appliance, after all possible rebates, credits, and other deductions. In other words, ignore any energy and other rebates, credits, and other deductions when making the choice." For the "estimated yearly operating cost," we noted that it "lists the estimated annual energy cost of the water heater option considered." For the EnergyGuide label, we indicated that "energy use is described using the EnergyGuide label administered by the Federal Trade Commission, the nation's consumer protection agency. EnergyGuide label can help you compare the energy use of different models as you shop for an appliance. The more energy efficient an appliance is, the less it costs to run, and the lower your utility bills."
} 
The range of potential annual operating costs assigned to different appliance options matched the information available for water heaters in the EnergyGuide final rule notice by the Federal Trade Commission (2007). . Because the yearly operating cost of water heaters substantially varies by the fuel used by the water heaters, we designed the entire survey, including information in the energy-labeling alternatives, to match the fuel type of the water heater in the respondent's home. This was achieved with an automated survey instrument in which the final instrument design is determined midsurvey using respondent-provided information on the fuel of the water heater in the respondent's home. The two primary fuels are natural gas (49 percent of the sample) and electricity (41 percent of the sample). The range of the annual operating cost attribute for water heaters by fuel is given in Table A1 in the appendix.

The range of purchase prices matched the range of actual purchase prices of water heaters available from the chief appliance retailers (Sears, Best Buy, Lowe's, and Home Depot). Using estimates developed by PG\&E, ${ }^{6}$ we determined the $\mathrm{CO}_{2}$ emissions to match the actual $\mathrm{CO}_{2}$ emissions from different appliance options presented (energy use and fuel determine $\mathrm{CO}_{2}$ emissions). However, in two treatments where this could be achieved without confounding the choice problem (i.e., the treatments with the carbon footprint), we randomized information on the $\mathrm{CO}_{2}$ emissions so that estimating preferences for $\mathrm{CO}_{2}$ emissions, independent of annual operating cost and energy use, became feasible. ${ }^{7}$

Summing up, each water heater option evaluated in the survey is realistic compared to the options currently on the market. Moreover, the range of energy use, purchase price, and $\mathrm{CO}_{2}$ emissions of water heaters examined in the overall survey corresponds to the range of options actually on the market. Table 1 provides descriptive statistics on the attributes of the products in our sample.

\section{Statistically Efficient Experimental Design of the Choice Sets}

Altogether, we developed 100 different potential instrument designs for each labeling treatment. Within each of the 12 treatments, instruments varied only in the attribute levels associated with each product model presented (i.e., purchase price, energy use, operating cost,

\footnotetext{
${ }^{6}$ See the PG\&E Carbon Footprint Calculator: http://www.pge.com/about/environment/calculator.

${ }^{7}$ Otherise, annual energy cost and $\mathrm{CO}_{2}$ emissions are perfectly correlated, so their effects on choices cannot be separately identified.
} 
and/or $\mathrm{CO}_{2}$ emissions). The choice sets in the 100 potential designs were constructed using Bayesian methods for statistically efficient experimental design (Kessels et al. 2006, 2009; Ferrini and Scarpa 2007; Sandor and Wedel 2002). Because the statistical efficiency of discrete choice models is not guaranteed by the orthogonality of experimental design, but also depends on the underlying choice probabilities, we developed a GAUSS program for a Monte Carlo modified Fedorov design algorithm to identify an experimental design that maximizes the statistical efficiency (D-efficiency) of the parameter estimates in a multinomial logit model. We used results from the literature (Brownstone and Train 1999) to inform the experimental design of the pilot experiments. We reevaluated the design after the pilot, but maintained it because the identification of treatment effects worked well in practice. Similar experimental designs over different treatments also helped the identification of treatment effects.

The purchase price and yearly operating cost of each alternative was drawn from seven potential levels within the ranges shown in Table A1 in the appendix. Each choice problem included three alternatives, none of which was strictly dominant relative to the other two alternatives. In other words, a water heater option could not be simultaneously less expensive to purchase and more energy efficient than the other two water heater options in the same choice question. This reflects the situation in the actual marketplace and was necessary to make the hypothetical choice situation realistic to the study participants. Because this design introduces correlation between the "yearly operating cost/energy use" and "purchase price" attributes, which may deteriorate estimation efficiency, we incorporated a nondominance requirement in the experimental design algorithm so that one could identify correlated experimental designs least detrimental to estimation efficiency.

Given that we used an individualized experimental design, examined 12 different labeling treatments, and customized the survey instrument design by fuel (natural gas or electricity), the survey required the development of 2,400 different survey instruments. Although this is beyond what is conventionally evaluated in choice experiments, it was beneficial for the estimation of the parameters of interest and is feasible using computerized experiments.

\section{Elicitation of Individual-Specific Discount Rates}

Our goal in the design of the intertemporal payment choice experiment was to match the relevant temporal and monetary scale of an appliance choice decision. We always used $\$ 1,000$ for payment A, (explained to respondents intuitively as a tax-free cash credit), because it is a round sum roughly comparable to the magnitude of investment required to purchase a new water heater. Following previous research on eliciting individual discount rates, which suggests that 
making the near-term payment immediately available may result in unreliable estimates of longer-term discount rates (Coller and Williams 1999), we made payment A available after a one-month period. Moreover, the scheduling of the payments in 1 and 12 months keeps the choice problem intuitive and reflects the relatively long time horizon relevant in the water heater purchase decision compared to many other decisions posed in the experimental literature on time preferences.

We introduced the payment choice problem to the study participants as follows.

“Think next that your household receives a \$1,000 tax-free cash credit. You will be given the credit as a $\$ 1,000$ check mailed to your address one (1) month from now. However, you can also opt for a higher credit amount mailed to you twelve (12) months from now. The credit in twelve months is higher to compensate you for agreeing to wait for the credit. You can only receive one credit. Both credits are certain to be delivered at their due date, and you will not need to pay tax on either one of them. The only difference between the credits is the delivery date and the payment amount."

Thereafter, a series of payment choices was presented, each payment choice with only two payment alternatives: $\$ 1,000$ available in 1 month and a greater amount available in 12 months. Each respondent checked the box next to the payment option he or she preferred in each comparison. Altogether, we used 18 different payment B amounts. They were determined using gradually increasing discount rates, starting with 2 percent $(\$ 1,019)$ and reaching up to 100 percent $(\$ 2,501)$. For discount rates between 2 and 20 percent, we used intervals of 2 percentage points between different payment $\mathrm{B}$ amounts. For discount rates between 20 and 30 percent, we increased the interval to 5 percentage points. Thereafter, the interval width increased to 10 percentage points until the 60 percent discount rate. Finally, we also included two payment choices constructed using 75 percent and 100 percent discount rates.

After making an initial choice between payment, A or B, each respondent who chose payment A continued through new payment-choice problems, each of which included a larger payment B. The payment choice problem continued until the respondent switched from choosing payment A to choosing payment $\mathrm{B}$. Table $\mathrm{A} 2$ in the appendix lists the different payment amounts used in the payment choice experiment. Table 1 provides descriptive statistics on the elicited discount rates. The mean rate was 19 percent, the median rate was 11 percent, and the standard deviation was 23 percent.

Many studies have estimated discount rates using field and laboratory data on, for example, health- and finance-related choices (Frederick et al. 2002). Although these studies 
mostly estimate relatively high discount rates, the range of estimates is wide. In the context of long-term choices (from several months to several years), the estimated discount rates vary from no more than 10 to 20 percent (e.g., Green et al. 1997; Cairns and van der Pol 1997; Wahlund and Gunnarson 1996) to 100 percent or more (e.g., Thaler 1981; Loewenstein 1987). However, among those studies using elicitation methods similar to ours, the results align closely with our estimates. Coller and Williams (1999), whose elicitation method we apply, estimate a median discount rate of 17 to 20 percent using a sample of students. Harrison et al. (2002) use the Coller and Williams (1999) elicitation method in a field experiment in Denmark, predicting a 28 percent discount rate, on average. Therefore, the level of discount rates we find for homeowners is consistent with other similar experimental evidence on discount rates.

\section{Discrete Choice Econometric Model in Willingness to Pay Space}

\section{Conceptual Model}

Using the random utility model (McFadden 1974, 1984) as the point of departure to the econometric modeling of the elicited choice data, we consider an individual $i$ choosing the preferred alternative from a set of $m$ alternatives. The utility that person $i$ derives from alternative $j$ is denoted $U_{i j}$. It can be additively separated into an unobserved stochastic component $\varepsilon_{i j}$ and a deterministic component $V_{i j}$, the indirect utility function, so that $U_{i j}=V_{i j}+\varepsilon_{i j}$. To model utility in the context of our choice experiments, we specify $V_{i j}$ as a linear additive function of the purchase price $(p)$, present value of annual operating cost (PVOC), and nonmonetary attributes $X$ of a water heater option $j$ :

$$
U_{i j}=\alpha_{i} p_{i j}+\beta_{i} P V O C_{i j}+\theta_{i} X_{i j}+\varepsilon_{i j}
$$

The water heater's $P V O C$ is determined as

$$
P V O C_{i j}=A_{i j}\left[1-\frac{1}{\left(1+r_{i}\right)^{n}}\right] \frac{1}{r_{i}},
$$

where $A$ is the annual operating cost included in most of the energy labels, $r$ is the discount rate, and $n$ is the planning horizon (taken to be 13 years, the typical lifetime of a water heater). Note that $r$ varies by individual, reflecting the subjective discount rate of each individual or household elicited through the cash-over-time choice task. We also estimate a version of the model where $P V O C$ is 
calculated assuming a uniform 5 percent discount rate across all individuals, which lies midway between the 3 percent and 7 percent rates used for government regulatory analysis. ${ }^{8}$

We assume that $\varepsilon_{i j}$ are type I extreme value random variables with variance $\mu_{i}^{2}\left(\frac{\pi^{2}}{6}\right)$, where $\mu$ is a scale parameter. As is standard, we divide equation (1) by $\mu$, leaving the model behaviorally unaffected and resulting in a new error term variance given by $\pi^{2} / 6$ (Train and Weeks 2005). Denoting $\lambda=\alpha / \mu, \omega=\beta / \mu$, and $\varphi=\theta / \mu$, utility is written as

$$
U_{i j}=\lambda_{i} p_{i j}+\omega_{i} P V O C_{i j}+\varphi_{i} X_{i j}+\varepsilon_{i j}
$$

Equation (3) specifies the model in utility (or preference) space, incorporating a scale parameter implicit in all coefficients.

WTP for improved energy efficiency (reduced PVOC), our key interest, is given by the ratio between the coefficients for the purchase price and PVOC, denoted here as $\gamma=\omega / \lambda$. WTP for nonmonetary attributes is determined similarly, denoted here as $\eta=\varphi / \lambda$. WTP relationships can also be directly incorporated into the utility model by rewriting equation (3) in "WTP space," following (Train and Weeks 2005):

$$
U_{i j}=\lambda_{i}\left[p_{i j}+\gamma_{i} P V O C_{i j}+\eta_{i} X_{i j}\right]+\varepsilon_{i j}
$$

Although equations (3) and (4) are behaviorally equivalent, equation (4) allows for a more intuitive and useful interpretation of the parameters of key interest in this study, which is to examine households' subjective valuation of energy efficiency. By using equation (4) for estimation, we can observe trade-offs implicit in households' choices between upfront investment costs and long-term savings associated with energy efficiency directly from the estimated model coefficients.

Note that equation (4) expresses the operating cost of the appliance option, $P V O C$, using the present value, calculated using equation (2) from the yearly operating cost communicated on the label. Therefore, for a "rational" cost-minimizing household exhibiting discount rate $r_{i}$, WTP for a $\$ 1$ reduction in PVOC should equal $\$ 1$ of purchase price. This requires that $\gamma=1$, indicating a one-to-one trade-off between purchase price and PVOC.

\footnotetext{
8 There is a subtlety here regarding nominal versus real discount rates. In government regulatory analysis, the 3 percent and 7 percent benchmarks are real rates. In this experiment, we did not specify what the respondents should assume about inflation, so their responses implicitly represent nominal rates and incorporate whatever their subjective inflation expectations might be.
} 
To complete the estimation framework, we note that choices are based on utility comparisons among the available alternatives, such that the alternative providing the highest utility is chosen. The probability of person $i$ choosing alternative $j$ from among the three alternatives therefore equals the probability that alternative $j$ provides person $i$ with a greater utility $U_{i j}$ than any other available alternative in the choice set:

$$
P_{i j}=P\left(U_{i j}>U_{i k}, k=1,2,3, \forall k \neq j\right) .
$$

We predict response probabilities using a flexible mixed logit model, which allows the preference parameters $\gamma_{i}$ and $\eta_{i}$ to vary within the population rather than be fixed at the same value for each person. Combining equations (3)-(5) and using $\Gamma=[\lambda, \gamma, \eta]$ to denote the vector of estimated parameters then yields the mixed logit $\operatorname{model}^{9}(\mathrm{McFadden}$ and Train 2000; Brownstone and Train 1999; Train 2003), and the probability of person $i$ choosing alternative $j$ out of $m$ alternatives is writtenas:

$$
P_{i j}=\int\left[\frac{\mathrm{e}^{V_{i j}}}{\sum_{k=1}^{k=3} \mathrm{e}^{V_{i k}}}\right] f(\Gamma \mid \Omega) d \Gamma .
$$

We approximate the above choice probability using simulation (Train 2003). Using $R$ draws of $\Gamma_{i}$ from $f(\Gamma \mid \Omega)$ and denoting the probability of the observed response sequence as $P_{i r}$, the simulated probability is determined as $S P_{i}(\Gamma)=\frac{1}{R} \sum_{r=1}^{r=R} P_{i r}$. To improve estimation, we generate Halton sequences and incorporate them in the simulation routine (Feenberg and Skinner 1994; Bhat 2002; Train 2003). ${ }^{10}$ Because each study participant in our experiment was subjected to six independent choice problems, we estimate the joint probability of observing the choice sequence elicited from each respondent. Denoting the choice problem by $h$, the simulated log-likelihood function is determined as:

$$
\log \mathrm{L}=\sum_{i=1}^{N} \ln \left(\prod_{h=1}^{6} S P_{i j h}\right)
$$

\footnotetext{
${ }^{9}$ The mixed logit model has other advantages in addition to random taste variation, including unrestricted substitution patterns and correlation in unobserved factors over time (Train 2003).

${ }^{10} \mathrm{We}$ use 250 Halton draws in all estimations. We have estimated the main models also using 500 and 1,000 Halton draws and find that the model results remain robust.
} 
Using the above estimation framework with varying preference parameters among different individuals enables us to accommodate the many different potential drivers of heterogeneity relevant to different respondents. Heterogeneity can arise from genuine taste differences, but could also be related to several other potential differences among respondents and their situations, including the likelihood of moving to another home and each person's perception of the degree to which benefits from an investment in energy efficiency may be recoverable in a home sale. Heterogeneity could also be associated with differences in each respondent's willingness and ability to pay attention to and process information in the label. ${ }^{11}$

\section{Empirical Specification}

According to equation (4), cost-minimizing trade-offs between PVOC and purchase price require that $\gamma=1$. To examine this equality under different labeling programs, we reparameterize $\gamma$, the WTP coefficient on PVOC, so that it becomes a function of the information treatment. We use the following seven indicator variables (denoted below with the subscript INFO) to describe variation in the labeling treatments included in the experiment:

1) any operating cost information included (yes/no)

2) continuous operating cost information included (yes/no)

3) EnergyGuide image included (yes/no)

4) Energy Star logo included (yes/no)

5) physical energy information (therms, $\mathrm{kWh}$ ) included (yes/no)

6) $\mathrm{CO}_{2}$ emissions information included (yes/no)

7) relative energy efficiency grade information included (EU-style label; yes/no)

Each of the 12 labeling treatments is assigned a set of seven $0-1$ indicator variables $Z_{1}, Z_{2}$, ..., $Z_{7}$ (see Appendix Table A5). Each of these seven dummy variables equals 1 if the specific

\footnotetext{
${ }^{11}$ Besides using the random coefficient formulation we develop here, one can account for individual parameter heterogeneity by using information on the observable characteristics of the respondent. As a robustness check, we also estimated our main models including individual heterogeneity as a product of the socioeconomic background of the respondent (age, income, education, employment status, gender, and geographic region). We estimated the model by reparametrizing the purchase cost parameter as a function of these characteristics. We estimated, while also allowing for random coefficients for the label attribute variables, thus introducing a rich structure for different forms of hetrerogeneity. These models suggest that, although both unobservable (random coefficients) and observable (socioeconomic characteristics) forms of heterogeneity may be present, our main results - the estimated effects from different label attributes - are robust to the inclusion of observable heterogeneity.
} 
characteristic 1-7 above is included in the labeling option; otherwise, the dummy variable is 0 . In the specification, these dummy variables are each interacted with PVOC, allowing the WTP for PVOC (i.e., $\gamma_{i}$ ) to be a function of the available information as follows:

$$
\gamma_{\mathrm{i}}=\sum_{I N F O=1}^{7} \hat{\gamma}_{i, I N F O} * Z_{i, I N F O}
$$

Each of the seven information coefficients is estimated flexibly as a random parameter so that the effect of information treatment may vary among individuals. We assume that random parameters are distributed normally and estimate the mean and standard deviation of the distribution of each random parameter.

Additionally, the experimental design and estimation framework enables us to independently identify WTP for $\mathrm{CO}_{2}$ emissions (tons per year), electricity usage ( $\mathrm{kWh}$ per year), natural gas usage (therms per year), the Energy Star logo along with other information, and the Energy Star logo alone. These effects are estimated through the addition of five variables alongside the PVOC terms (i.e., the vector of $X$ in equation [4]), three of which are continuous random parameters ( $\mathrm{kWh}$, therms, and $\mathrm{CO}_{2}$ emissions) and two of which are discrete fixed parameters (the Energy Star logo indicators). ${ }^{12}$

\section{Results}

Our mixed logit estimation results are given in Table 2 and 3 based, respectively, on discounting operating costs using individual-specific discount rates and a constant 5 percent discount rate for all individuals. For information treatments, the tables list both the estimated mean and the standard deviation of the coefficient distribution, given the random coefficient approach to estimation. To provide a normalized sense of the degree of variation in the coefficient estimates, we also list the coefficient of variation (i.e., the standard deviation divided by the mean) for each random-parameter distribution. Estimation employing a fixed-parameter model shows similar results, which are given in the appendix in Tables A3 and A4.

\footnotetext{
12 Our econometric specification with a large number of random parameters and our estimation in the WTP space is demanding for identification in practice; we therefore restrict the Energy Star dummies to being fixed to assist in estimation. Robustness checks indicate that this specification choice has minimal impact on the remaining estimation results.
} 
We find a statistically significant effect on appliance choice of information on the purchase price, energy operating cost, Energy Star qualification, physical energy use (i.e., kWh or therms), $\mathrm{CO}_{2}$ emissions, and energy efficiency "letter grade". This is indicated by the statistically significant estimated mean coefficient of the parameter distribution for the above information treatments. The presence of information on the operating cost relative to a range of comparable models and the yellow EnergyGuide image, however, did not have a consistently significant effect on choice. ${ }^{13}$ Note also that, for attributes entering both interacted with operating costs and alone (e.g., the Energy Star logo), the associated coefficient estimates need to be considered together to assess the overall impact of that information element.

The estimated standard deviations of the coefficient distributions are also generally statistically significant for the information treatments for which the estimated distribution mean parameters are statistically significantly different from zero. This indicates that the effect of information varies by individual. The coefficients of variation of the coefficient distributions vary roughly between 0.1 and 0.9 , suggesting that the degree of individual variability in the effect of information varies considerably by information treatment. As a robustness check on the current results, we estimated both the random- and fixed-parameter models with demographic variables alongside the main variables of interest (see footnote 11). The results of interest were robust to the inclusion of these demographic variables, which was expected given the random nature of the experimental design. As another robustness check, we also estimated the model excluding observations with extremely high (more than 50 percent or 75 percent) and low (less than 2 percent) individual discount rates. The results are robust also to this change in the sample.

Recall that each of the coefficients, other than that on purchase price, has been normalized by the coefficient on purchase price to yield more easily interpreted estimates expressed in dollars of WTP. For the information attributes interacted with discounted operating costs, the interpretation of the coefficients is dollars of WTP per dollar saved in discounted operating costs. It is easiest to interpret the magnitude of these information attributes as combined information-labeling treatments, which we do below in Table 4. Table 4 summarizes the estimated WTP for discounted operating cost savings for six composite labeling treatments,

\footnotetext{
${ }^{13}$ Note that the estimated effects of these two information elements tended to be closely related. In the estimation using a constant 5 percent discount rate, both were close to zero in magnitude and were statistically insignificant. In the estimation using individiual-specific discount rates, each was larger in magnitude (with the EnergyGuide image having a counterintuitive negative sign), but the combined effect was again close to zero and statistically insignificant.
} 
based on the results in Table 2 and 3. These labeling treatments, which are illustrated in Figure 4, represent a sufficient subset of the 12 treatments actually used in the experiment to illustrate the key results.

It is helpful to compare the estimated WTP to a value of 1 because it indicates costminimizing behavior, in which equal weight is given to changes in the purchase price and the discounted operating cost savings. In contrast, a value less than 1 indicates relative undervaluation of energy savings, whereas a value greater than 1 represents overvaluation of energy savings. The classic energy efficiency gap or energy paradox is associated with values less than 1 . Note that the results using individual discount rates consistently indicate a greater degree of relative value attached to discounted energy cost savings compared to a 5 percent rate. This is because the individual rates are higher, on average, than 5 percent — with a median value of 11 percent and mean value of 20 percent - and will therefore appropriately attach lower discounted value to energy savings under cost-minimizing behavior.

Information-labeling treatment A includes only simple operating cost information and yields an estimated WTP for discounted operating cost savings of 0.80 when employing individual discount rates and 0.56 when using a 5 percent rate. Although this suggests a significant degree of undervaluation of energy efficiency when only modest information is available, it also indicates how potent even modest information can be. Adding information on the relative operating cost range of comparable models and the yellow EnergyGuide image (Label B) does not significantly add to the basic information value already given by Label A.

Adding $\mathrm{CO}_{2}$ emissions information in Label $\mathrm{C}$ provides a further boost to the relative value of energy savings, but is not as individually important as the direct monetary value of energy cost reductions. Information on $\mathrm{CO}_{2}$ emissions is particularly heterogeneous in its effect on WTP for reduced operating costs (see Tables 2 and 3). Although the mean of the coefficient distribution associated with the $\mathrm{CO}_{2}$ information treatment is positive, it is only about one standard deviation away from zero (using both individual and 5 percent discount rates). Because the coefficient is estimated using a normal distribution, this result suggests that, for about 15 percent of the population, the presence of $\mathrm{CO}_{2}$ information decreases WTP for lower operating costs. This finding is consistent with the experience of energy efficiency marketers (based on anecdotal conversations with the authors) and with recent research by Gromet et. al (2013), demonstrating how promoting the environment can negatively affect the adoption of energy efficiency in the United States because of the political polarization surrounding environmental issues. For the rest of the population, the effect of the presence of $\mathrm{CO}_{2}$ information in the label increases WTP for reduced operating costs in our study. 
Label $\mathrm{D}$ is the same as $\mathrm{C}$ except that $\mathrm{CO}_{2}$ information is replaced by physical energy use, in $\mathrm{kWh}$ or therms depending on whether the individual uses electricity or natural gas for water heating. Physical energy use information adds a value of energy savings similar to that added by $\mathrm{CO}_{2}$ information, but again, not as much as monetary information on energy costs. Label D represents the current EnergyGuide label mandated by US regulation, so it is worth further reflection. Using individual discount rates, Label D leads to choices placing a relative value of 1.04 on energy cost reductions compared to reductions in the purchase price. This is very close to cost-minimizing behavior - assuming one takes the individual discount rates as an appropriate indication of time preferences. If, on the other hand, one questions the relatively high individual discount rates and instead uses a 5 percent rate, Label D is still associated with choices that significantly undervalue discounted energy savings: they are roughly one-third lower in value than the value associated with saving on the equipment purchase price. The issue of the appropriate discount rate to use for energy efficiency analysis (and benefit-cost analysis more generally) once again exhibits its importance.

Label E adds the Energy Star logo to Label D for qualified models. ${ }^{14}$ The Energy Star endorsement significantly raises the value placed on energy efficiency and, using a 5 percent rate, the Energy Star logo supplementing the other information yields a relative WTP for energy savings (1.23) that is now somewhat greater than with cost-minimizing behavior. Assuming one uses individual discount rates, the Energy Star endorsement raises the importance of energy efficiency by an even greater degree, to the point where individuals placed substantially higher private value on discounted operating costs than on purchase costs (i.e., the relative WTP is 1.50). Also note from Tables 2 and 3 that the Energy Star logo induces a discrete positive inclination toward energy efficiency, while dampening the continuous incentive associated with varying operating costs (i.e., the coefficient on Energy Star interacted with operating costs is negative).

\footnotetext{
14 The coefficients on the indicators that a model was Energy Star-qualified are interpretable simply as incremental dollars of WTP relative to a model that is not Energy Star-qualified. In cases where the only information presented was an Energy Star logo, we found an incremental WTP of \$667 using individual discount rates and \$663 using a constant 5 percent rate across all individuals. To place this in perspective, the average Energy Star-qualified model saved \$109 per year in energy operating costs relative to a non-Energy Star model. The present value of this savings is $\$ 733$ using the average individual discount rate or $\$ 1,019$ using a 5 percent rate. Thus, the ratio of WTP for an Energy Star model to the value of its discounted energy cost savings was 0.91 using individual discount rates and 0.65 using a 5 percent rate. This is for labels on which only the Energy Star logo was presented. In Label E, for example, on which other information was presented as well, one needs to add the discrete impact of Energy Star to the impact of the other information attributes, as in Table 4.
} 
Label F, which bears an EU-like energy efficiency letter grade, yields results similar to those of the current US label plus Energy Star logo (i.e., Label E) — that is, somewhat beyond cost-minimizing behavior using a 5 percent discount rate and substantial overvaluation of energy savings using individual discount rates. Note that the EU-style label includes a letter grade from A to $\mathrm{G}$, which suggests that the lower the energy use the better. Even with a relatively simple indication of energy operating cost and no other information, this suggestive label has a powerful effect. Anyone who has been to school wants to get an A rather than a C or F.

For the information attributes (shown in the lower half of Tables 2 and 3) that express continuous physical information (i.e., $\mathrm{kWh}$, therms, and $\mathrm{CO}_{2}$ ), the interpretation of the coefficients is in dollars of WTP per unit (i.e., $\mathrm{kWh}$, therms, and $\mathrm{CO}_{2}$ ) saved per year. To provide a useful interpretation of these physical coefficients, one must first divide the coefficient by a present value factor, thereby yielding a WTP estimate that is measured simply in dollars per unit; we do this in Table 5. The results are quite interesting and show an almost surprising degree of economically sensible valuations. The estimated WTP for reductions in electricity use was $8.0 \notin$ per $\mathrm{kWh}$ and $11.8 \notin$ per $\mathrm{kWh}$ (for 5 percent and individual discount rates, respectively). To put these values in context, note that the residential average retail price of electricity in 2010 was $11.5 \notin$ per $\mathrm{kWh}$ - almost exactly the same as the valuation estimated from our data using individual discount rates. Moreover, one must keep in mind that these values were based purely on the exposure of the respondent to information on annual electricity use, estimated solely from the treatments that included only physical measures of energy use (in $\mathrm{kWh}$ rather than dollars; see treatments 3 and 11 in Appendix Figure A1).

This suggests that, although physical energy information alone is not sufficient to guide informed economic decisions, households are able to translate between physical energy and its economic value. Similarly, the estimated WTP for reductions in natural gas use was $\$ 0.84$ per therm and $\$ 1.16$ per therm (for 5 percent and individual discount rates, respectively) - compared to a $\$ 1.14$ per therm residential average retail price of natural gas in 2010. Again, these estimates suggest a high degree of economically sensible valuations in the stated preference context. Finally, the mean WTP estimate for $\mathrm{CO}_{2}$ reductions is approximately $\$ 12$ per ton and $\$ 18$ per ton for the 5 percent and individual discount rates, respectively. Although this does not necessarily provide further evidence of individually rational valuations $-\mathrm{CO}_{2}$ emissions are not commonly valued through markets - this estimate of the private valuation of $\mathrm{CO}_{2}$ reductions is close to the range of central estimates of the near-term social cost of carbon, which tend to range from $\$ 20$ to $\$ 30$ per ton of $\mathrm{CO}_{2}$. 


\section{Conclusion}

This paper evaluates the effectiveness of information provision through energy efficiency labeling in improving energy efficiency decisions by households. By coupling a carefully designed choice experiment with information on all key elements of intertemporal energy efficiency choices, we are able to disentangle the roles played by (a) different types of information and (b) intertemporal behavior (i.e., discounting) in guiding energy efficiency behavior. Virtually all previous research has been limited in its ability to isolate and understand the nature of the energy efficiency gap due to the need in those studies to make assumptions about some elements of the choice decision in order to evaluate claims about other elements of the decision.

We find that simple information on the economic value of saving energy is the most important element guiding more cost-efficient investments in appliance energy efficiency - that is, investments that place equal value on saving $\$ 1$ in purchase price or present value operating costs. Adding more complex economic information to place these operating costs within the cost range of available models did not have significant additional value. Information on the amount of physical energy an appliance uses had incremental value in guiding decisions, but was of less importance than the monetary information. Information on $\mathrm{CO}_{2}$ emissions also had incremental value, but was of still lesser importance than the physical and economic information. We also were able to elicit WTP estimates for $\mathrm{CO}_{2}$ emissions reductions of roughly $\$ 10$ to $\$ 20$ per ton.

Bringing these elements together, we find that the degree to which the current EnergyGuide label guided cost-efficient decisions depends on the discount rate assumed appropriate for the analysis. Using the individual discount rates separately elicited in our study (which had median and mean values of 11 and 20 percent, respectively), we find that the EnergyGuide label came very close to guiding cost-efficient decisions, on average-choices that were not statistically different from placing equal weight on up-front purchase costs and discounted operating costs. In contrast, using a uniform 5 percent rate for discounting-which is much lower than the average individual elicited rate - we find that the EnergyGuide label resulted in choices that placed too little weight on energy operating cost savings, resulting in a one-third undervaluation of energy efficiency. Information treatments with less economic or physical energy information than in current US labeling led to an even greater degree of undervaluation, resulting in too little weight being placed on energy operating costs, regardless of the discount rate used. 
Interestingly, we find that labels that not only nudged people with dispassionate monetary or physical information, but also endorsed a model (with Energy Star) or gave a suggestive grade to a model (as with the EU-style label), had a substantial impact on encouraging choices with higher energy efficiency. Moreover, depending again on one's view of the appropriate discount rate, these more suggestive labels yielded choices that placed a greater incremental value on discounted energy than on purchase cost to either a moderate (using a uniform 5 percent rate) or substantial degree (using individually elicited discount rates).

These results reinforce the centrality of one's view on intertemporal choice and discounting, both in terms of understanding individual behavior and in guiding public policy decisions. Using additional information gathered in our survey (e.g., on consumer interest rates and payback thresholds), a companion paper further explores individual behavior related to the intertemporal trade-offs involved in energy efficiency decisions. Finally, our estimation approach finds considerable heterogeneity in individual valuation of information related to energy efficiency decisions, particularly the valuation of information related to $\mathrm{CO}_{2}$ emissions. 
Figures and Tables

Figure 1. Current EnergyGuide Label for Water Heaters

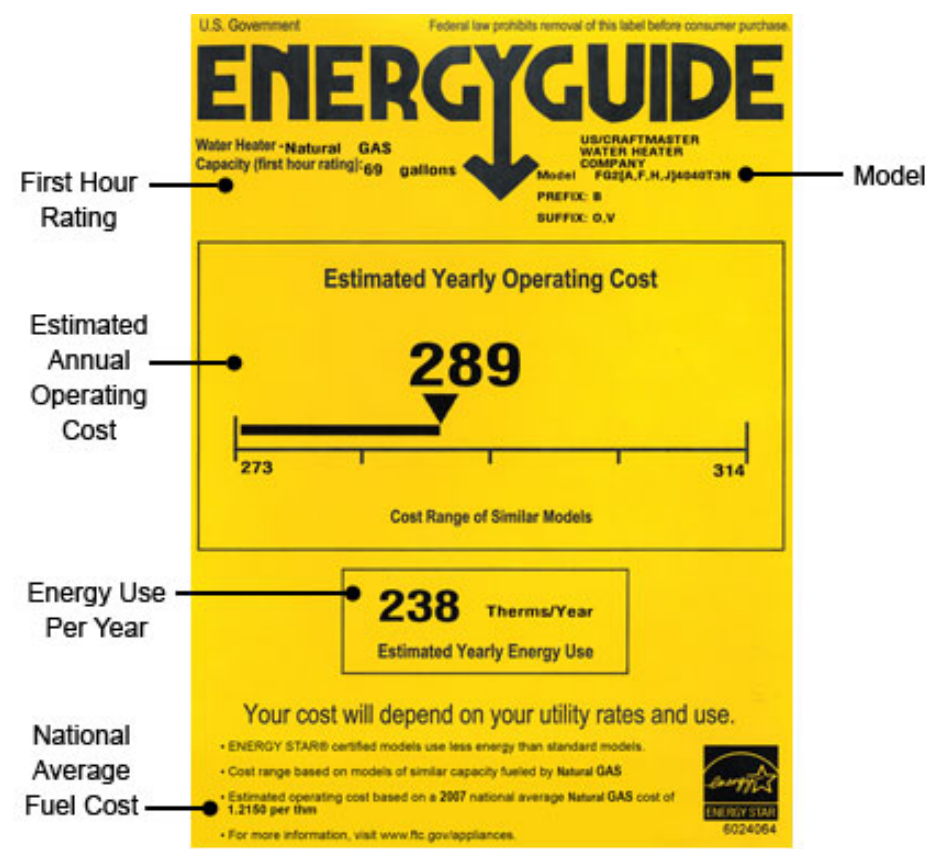

Figure 2. Energy Efficiency Grade Label

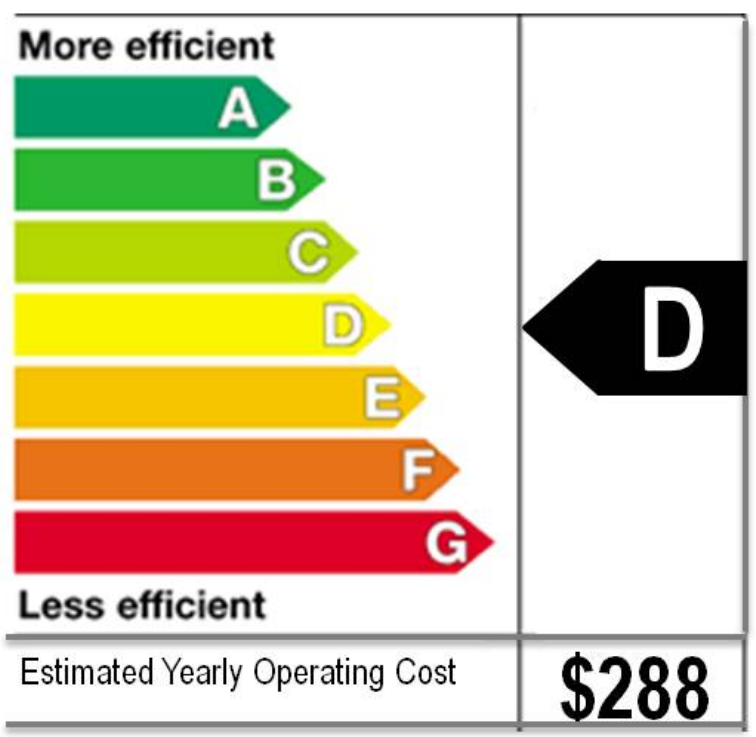


Figure 3. An Example of the Choice Screen in the Current EnergyGuide Labeling Treatment

Consider choosing between the following three water heater options. Please think that these are the only options available to you and you have to make the purchase.

Water Heater Decision 1

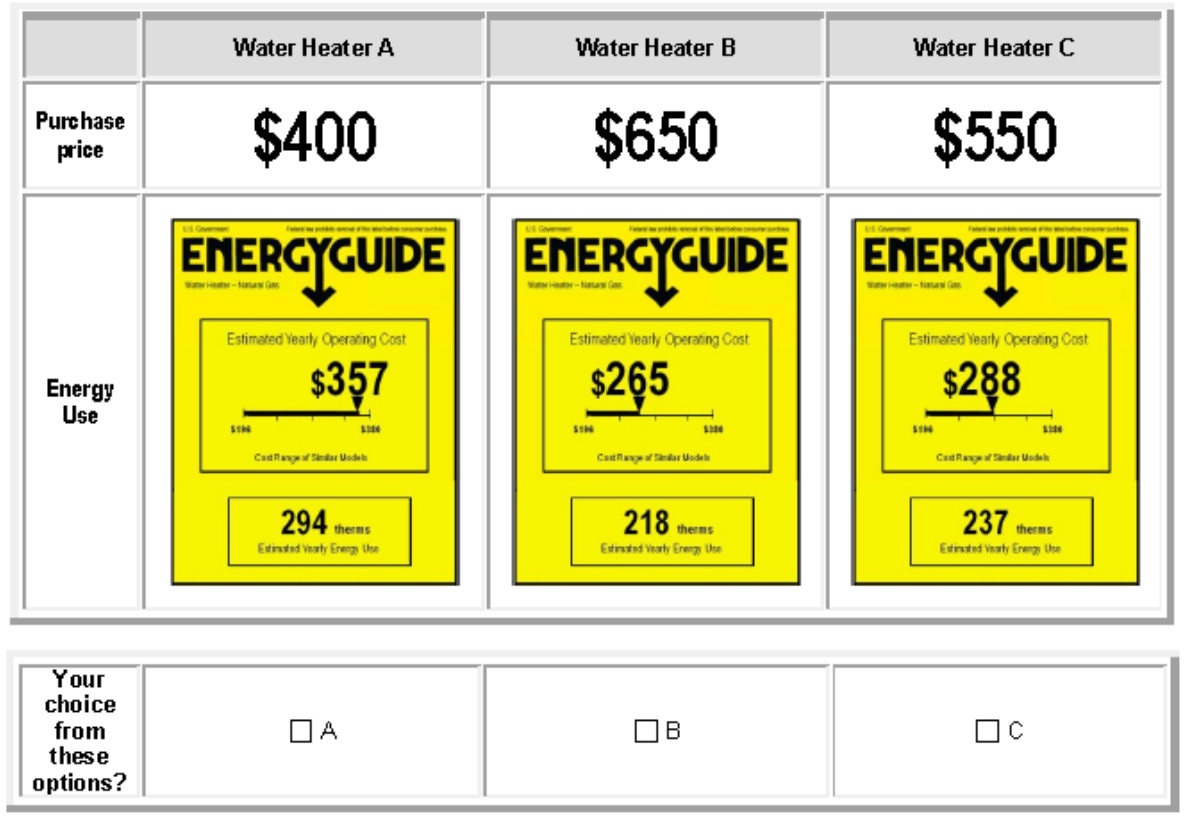

Figure 4. Graphical Depiction of the Six Composite Energy Labels (A-F) Evaluated

A

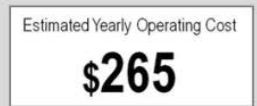

D

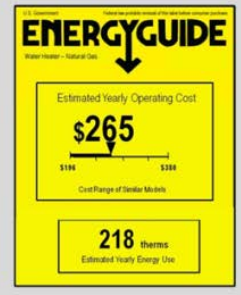

B

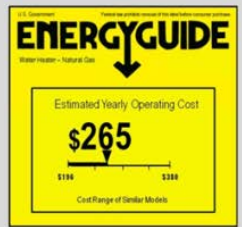

$E$

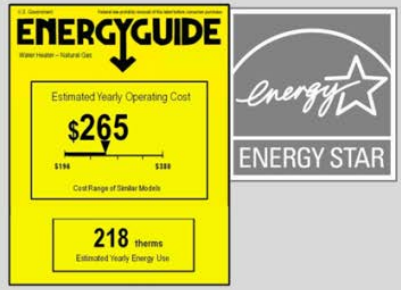

C

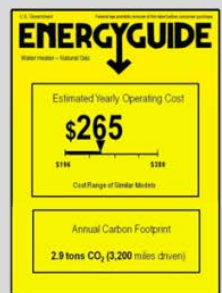

$\mathrm{F}$

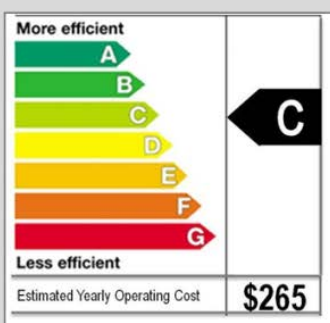


Table 1. Descriptive Statistics of the Sample and Estimation Variables

\begin{tabular}{|c|c|c|c|c|c|c|}
\hline Variable & Mean & $\begin{array}{l}\text { Standard } \\
\text { deviation }\end{array}$ & Median & Min & Max & $\begin{array}{l}\text { Comparison } \\
\text { (AHS 2011) }\end{array}$ \\
\hline \multicolumn{7}{|l|}{ Household characteristics } \\
\hline Household income (\$ per year) & 65,206 & 40,551 & 55,000 & 2,500 & $>\$ 200,000^{1}$ & 58,919 \\
\hline Metropolitan area (yes, no) & 0.82 & 0.38 & 1 & 0 & 1 & 0.82 \\
\hline Employed (yes, no) & 0.51 & 0.50 & 1 & 0 & 1 & $\mathrm{~N} / \mathrm{A}$ \\
\hline White/non-Hispanic (yes, no) & 0.80 & 0.40 & 1 & 0 & 1 & 0.78 \\
\hline Married (yes, no) & 0.64 & 0.48 & 1 & 0 & 1 & 0.60 \\
\hline $\begin{array}{l}\text { Education (bachelor's and } \\
\text { higher) }\end{array}$ & 0.40 & 0.49 & 0 & 0 & 1 & 0.35 \\
\hline Individual discount rate & 0.19 & 0.23 & 0.11 & 0.01 & 1.00 & $\mathrm{~N} / \mathrm{A}$ \\
\hline \multicolumn{7}{|c|}{ Water heater attributes in the choice experiments } \\
\hline Purchase price $(\$)$ & 953 & 386 & 930 & 420 & 1,440 & \\
\hline Annual operating cost $(\$)$ & 363 & 113 & 351 & 219 & 563 & \\
\hline PVOC@ $@$ \% discount rate $(\$)$ & 3,408 & 1,066 & 3,297 & 2,057 & 5,289 & \\
\hline $\begin{array}{l}\text { PVOC @ individual discount } \\
\text { rates }(\$)\end{array}$ & 2,285 & 1,284 & 2,131 & 219 & 6,819 & \\
\hline Energy usage (therms per year) & 223 & 39 & 218 & 180 & 275 & \\
\hline Energy usage (kWh per year) & 4,165 & 1,066 & 4,105 & 3,579 & 4,894 & \\
\hline
\end{tabular}

Notes: Income data uses a categorical variable. Binary variables assign 1 to yes and 0 to no. Values for comparison were derived from the 2011 American Housing Survey (AHS) using data for owner-occupied housing units (US Census Bureau 2012). PVOC, present value of annual operating cost. 
Table 2. Mixed Logit Estimation Results Using Individual-Specific Discount Rates

\begin{tabular}{|c|c|c|c|c|}
\hline \multirow[b]{2}{*}{ Variable } & \multirow[b]{2}{*}{$\begin{array}{c}\text { Units of } \\
\text { coefficient }\end{array}$} & \multicolumn{3}{|c|}{$\begin{array}{c}\text { Estimates of distribution parameters } \\
\text { (standard errors in parenthesis) }\end{array}$} \\
\hline & & Mean coefficient & $\begin{array}{c}\text { Standard deviation } \\
\text { coefficient }\end{array}$ & $\begin{array}{c}\text { Coefficient of } \\
\text { variation }\end{array}$ \\
\hline \multicolumn{5}{|c|}{ Information treatments and WTP for reduced PVOC } \\
\hline $\begin{array}{l}\text { Any operating cost } \\
\text { info. }\end{array}$ & \multirow{7}{*}{$\begin{array}{l}\text { \$ WTP per \$ } \\
\text { saved in } \\
\text { discounted } \\
\text { operating cost }\end{array}$} & $0.801(0.072)^{* *}$ & $0.102(0.022)^{* *}$ & 0.13 \\
\hline $\begin{array}{l}\text { Operating cost } \\
\text { relative to range }\end{array}$ & & $0.134(0.090)$ & $0.037(0.026)$ & not significant \\
\hline EnergyGuide image & & $-0.125(0.047)^{* *}$ & $0.024(0.014)^{*}$ & 0.19 \\
\hline Energy Star logo & & $-0.269(0.080)^{* *}$ & $0.171(0.023)^{* *}$ & 0.64 \\
\hline Physical energy info. & & $0.225(0.087)^{* *}$ & $0.206(0.024)^{* *}$ & 0.92 \\
\hline $\mathrm{CO}_{2}$ emissions info. & & $0.280(0.082)^{* *}$ & $0.248(0.021)^{* *}$ & 0.89 \\
\hline $\begin{array}{l}\text { Relative grade info. } \\
\text { (EU-style) }\end{array}$ & & $0.892(0.135)^{* *}$ & $0.328(0.034)^{* *}$ & 0.37 \\
\hline \multicolumn{5}{|c|}{ WTP for other attributes } \\
\hline $\begin{array}{l}\mathrm{CO}_{2} \text { emissions (tons } \\
\text { per year) }\end{array}$ & $\begin{array}{l}\$ \text { WTP per ton } \\
\text { saved per year }\end{array}$ & $1.180(0.240)^{* *}$ & $0.738(0.175)^{* *}$ & 0.62 \\
\hline $\begin{array}{l}\text { Electricity usage } \\
\text { (kWh per year) }\end{array}$ & $\begin{array}{c}\$ \text { WTP per kWh } \\
\text { saved per year }\end{array}$ & $0.794(0.091)^{* *}$ & $0.176(0.056)^{* *}$ & 0.22 \\
\hline $\begin{array}{l}\text { Natural gas usage } \\
\text { (therms per year) }\end{array}$ & $\begin{array}{l}\$ \text { WTP per kWh } \\
\text { saved per year }\end{array}$ & $7.85(0.63)^{* *}$ & $0.001(0.232)$ & not significant \\
\hline $\begin{array}{l}\text { Energy Star logo w/ } \\
\text { other info. }\end{array}$ & \$ WTP & $585(49)^{* *}$ & $\mathrm{n} / \mathrm{a}$ & $\mathrm{n} / \mathrm{a}$ \\
\hline $\begin{array}{l}\text { Energy Star logo } \\
\text { alone }\end{array}$ & \$ WTP & $667(37)^{* *}$ & $\mathrm{n} / \mathrm{a}$ & $\mathrm{n} / \mathrm{a}$ \\
\hline Purchase price $(\$)$ & utils per \$ WTP & $-27.8(0.7)^{* *}$ & $\mathrm{n} / \mathrm{a}$ & $\mathrm{n} / \mathrm{a}$ \\
\hline
\end{tabular}

Notes: Number of observations equals 1,214. Coefficients are estimated relative to the coefficient on purchase price, yielding coefficient estimates expressed in \$WTP per unit. Results are from a mixed logit model estimated using simulated maximum likelihood and 250 Halton draws. ${ }^{* *}$ and $*$ indicate statistical significance at the 1 percent and 5 percent levels, respectively. 
Table 3. Mixed Logit Estimation Results Using 5 Percent Discount Rates

\begin{tabular}{|c|c|c|c|c|}
\hline \multirow[b]{2}{*}{ Variable } & \multirow[b]{2}{*}{$\begin{array}{l}\text { Units of } \\
\text { coefficient }\end{array}$} & \multicolumn{3}{|c|}{$\begin{array}{c}\text { Estimates of distribution parameters (standard errors in } \\
\text { parenthesis) }\end{array}$} \\
\hline & & Mean coefficient & $\begin{array}{c}\text { Standard deviation } \\
\text { coefficient }\end{array}$ & $\begin{array}{c}\text { Coefficient of } \\
\text { variation }\end{array}$ \\
\hline \multicolumn{5}{|c|}{ Information treatments and WTP for reduced PVOC } \\
\hline $\begin{array}{l}\text { Any operating cost } \\
\text { info. }\end{array}$ & \multirow{7}{*}{$\begin{array}{l}\text { \$ WTP per \$ } \\
\text { saved in } \\
\text { discounted } \\
\text { operating cost }\end{array}$} & $0.559(0.043)^{* *}$ & $-0.059(0.012)^{* *}$ & 0.11 \\
\hline $\begin{array}{l}\text { Operating cost } \\
\text { relative to range }\end{array}$ & & $0.011(0.547)$ & $0.025(0.016)$ & not significant \\
\hline EnergyGuide image & & $-0.027(0.033)$ & $0.002(0.009)$ & not significant \\
\hline Energy Star logo & & $-0.149(0.060)^{*}$ & $0.038(0.014)^{* *}$ & 0.26 \\
\hline Physical energy info. & & $0.156(0.055)^{* *}$ & $0.011(0.019)$ & not significant \\
\hline $\mathrm{CO}_{2}$ emissions info. & & $0.158(0.049)^{* *}$ & $0.147(0.016)^{* *}$ & 0.93 \\
\hline $\begin{array}{l}\text { Relative grade info. } \\
\text { (EU-style) }\end{array}$ & & $0.632(0.091)^{* *}$ & $0.122(0.024)^{* *}$ & 0.19 \\
\hline \multicolumn{5}{|c|}{ WTP for other attributes } \\
\hline $\begin{array}{l}\mathrm{CO}_{2} \text { emissions (tons } \\
\text { per year) }\end{array}$ & $\begin{array}{l}\$ \text { WTP per ton } \\
\text { saved per year }\end{array}$ & $1.10(0.26)^{* *}$ & $0.917(0.171)^{* *}$ & 0.84 \\
\hline $\begin{array}{l}\text { Electricity usage } \\
\text { (kWh per year) }\end{array}$ & $\begin{array}{c}\$ \text { WTP per kWh } \\
\text { saved per year }\end{array}$ & $0.753(0.085)^{* *}$ & $0.185(0.056)^{* *}$ & 0.25 \\
\hline $\begin{array}{l}\text { Natural gas usage } \\
\text { (therms per year) }\end{array}$ & $\begin{array}{l}\$ \text { WTP per kWh } \\
\text { saved per year }\end{array}$ & $7.85(0.60)^{* *}$ & $0.003(0.460)$ & not significant \\
\hline $\begin{array}{l}\text { Energy Star logo w/ } \\
\text { other info. }\end{array}$ & \$ WTP & $580(57)^{* *}$ & $\mathrm{n} / \mathrm{a}$ & $\mathrm{n} / \mathrm{a}$ \\
\hline $\begin{array}{l}\text { Energy Star logo } \\
\text { alone }\end{array}$ & \$ WTP & $663(35)^{* *}$ & $\mathrm{n} / \mathrm{a}$ & $\mathrm{n} / \mathrm{a}$ \\
\hline Purchase price $(\$)$ & utils per \$ WTP & $-29.0(0.8)^{* *}$ & $\mathrm{n} / \mathrm{a}$ & $\mathrm{n} / \mathrm{a}$ \\
\hline
\end{tabular}

Notes: Number of observations equals 1,214. Coefficients are estimated relative to the coefficient on purchase price, yielding coefficient estimates expressed in \$WTP per unit. Results are from a mixed logit model estimated using simulated maximum likelihood and 250 Halton draws. ${ }^{* *}$ and $*$ indicate statistical significance at the 1 percent and 5 percent levels, respectively. 
Table 4. Summary of Estimated Relative WTP for Discounted Operating Cost Savings

\begin{tabular}{|l|c|c|}
\hline Information-labeling treatment & $\begin{array}{c}\text { Individual } \\
\text { discount rates }\end{array}$ & $\begin{array}{c}\mathbf{5 \%} \text { discount } \\
\text { rate }\end{array}$ \\
\hline A. Only simple operating cost information & 0.80 & 0.56 \\
\hline $\begin{array}{l}\text { B. Relative operating cost and EnergyGuide added to } \\
\text { treatment A }\end{array}$ & 0.81 & 0.54 \\
\hline C. $\mathrm{CO}_{2}$ information added to treatment B & 1.09 & 0.70 \\
\hline $\begin{array}{l}\text { D. Current label: Physical energy information added to } \\
\text { treatment B }\end{array}$ & 1.04 & 0.70 \\
\hline E. Current label plus Energy Star & 1.50 & 1.23 \\
\hline F. EU-style relative grade added to treatment A & 1.69 & 1.19 \\
\hline
\end{tabular}

Notes: Estimates are found by adding the relevant information attributes from Tables 1 and 2. For treatment E, which includes the Energy Star logo, we add the continuous impact of Energy Star to its discrete impact after dividing the latter by the present value of operating cost savings for the average Energy Star versus non-Energy Star model. 1.0 is equal weight, or cost-minimizing behavior; $<1$ is undervaluation of energy savings; and $>1$ is overvaluation of energy savings. 
Table 5. WTP Estimates for $\mathrm{CO}_{2}$ Emissions and Physical Energy Use Reductions, Based Solely on Exposure to Physical Information

\begin{tabular}{|l|c|c|c|}
\hline Variable & \multicolumn{2}{|c|}{ Estimate } & Comparison \\
\hline & $\begin{array}{c}\text { Individual discount } \\
\text { rates }\end{array}$ & $\begin{array}{c}5 \% \text { discount } \\
\text { rate }\end{array}$ & \\
\hline $\begin{array}{l}\mathrm{CO}_{2} \text { reductions } \\
(\$ / \text { ton })\end{array}$ & $\begin{array}{c}17.5 \\
(10.4-24.6)\end{array}$ & $\begin{array}{c}11.7 \\
(6.3-17.1)\end{array}$ & $\begin{array}{c}\$ 20-\$ 30 / \text { ton central estimates } \\
\text { for social cost of carbon }\end{array}$ \\
\hline $\begin{array}{l}\text { Electricity savings } \\
(\varnothing / \mathrm{kWh})\end{array}$ & 11.8 & 8.0 & $\begin{array}{c}11.5 \phi / \mathrm{kWh} \text { residential avg. } \\
\text { retail price in } 2010\end{array}$ \\
\hline $\begin{array}{l}\text { Natural gas savings } \\
(\$ / \text { therm) }\end{array}$ & $(9.1-14.4)$ & $(6.3-9.8)$ & 0.84 \\
\hline
\end{tabular}

Note: Estimates are found by dividing coefficients in Tables 1 and 2 by the present value factor using the average individual discount rate (factor $=6.75$ ) or a 5 percent discount rate (factor $=9.39$ ), as appropriate. 


\section{References}

Allcott, H. 2011a. Consumers' Perceptions and Misperceptions of Energy Costs. American Economic Review 101(3): 98-104.

Allcott, H. 2011b. Social Norms and Energy Conservation. Journal of Public Economics 95(910): 1082-95.

Allcott, H., and M. Greenstone. 2012. Is There an Energy Efficiency Gap? Journal of Economic Perspectives 26(1): 3-28.

Anderson, S.T., and R.G. Newell.2004. Information Programs for Technology Adoption: The Case of Energy-Efficiency Audits. Resource and Energy Economics 26: 27-50.

Bhat, C. 2002. Simulation Estimation of Mixed Discrete Choice Models Using Randomized and Scrambled Halton Sequences. Transportation Research Part B, Vol. 37: 837-855.

Brownstone, D., and K. Train. 1999. Forecasting New Product Penetration with Flexible Substitution Patterns. J. Econometrics 89: 109-29.

Cairns, J.A., and M.M. van der Pol. 1997. Constant and Decreasing Timing Aversion for Saving Lives. Social Sci. Med. 45(11): 1653-59.

Carson, R.T., N.E. Flores, K.M. Martin, and J.L. Wright. 1996. Contingent Valuation and Revealed Preference Methodologies: Comparing the Estimates for Quasi-Public Goods. Land Economics 72(1): 80-99.

Coller, M., and M.B. Williams. 1999. Eliciting Individual Discount Rates. Experimental Economics 2: 107-27.

Davis, L.W. 2010. Evaluating the Slow Adoption of Energy Efficient Investments: Are Renters Less Likely To Have Energy Efficient Appliances? Energy Institute at Haas Working Paper 205, June. Berkeley, CA: Energy Institute at Haas.

DeCanio, S.J., and W.E. Watkins. 1998. Investment In Energy Efficiency: Do the Characteristics of Firms Matter? Review of Economics and Statistics 80: 95-107.

Federal Trade Commission. 2007. Rule Concerning Disclosures Regarding Energy Consumption and Water Use of Certain Home Appliances and other Products Required Under the Energy Policy and Conservation Act ("Appliance Labeling Rule'); Final Rule. Federal Register vol. 72, No. 167: 49948-49997. August 29.

Feenberg, D., and J. Skinner. 1994. The Risk and Duration of Catastrophic Health Care Expenditures, Review of Economics and Statistics 76: 633-47.

Ferrini, S., and R. Scarpa. 2007. Designs with a Priori Information for Nonmarket Valuation with Choice Experiments: A Monte Carlo Study. Journal of Environmental Economics and Management 53: 342-63.

Fong, Christina M. and Erzo F.P. Luttmer. 2009. What determines giving to hurricane Katrina victims? Experimental evidence on racial group loyalty. American Economic Journal: Applied Economics 1(2): 64387. 
Frederick, S., G. Loewenstein, and T. O’Donoghue. 2002. Time Discounting and Time Preference: A Critical Review. Journal of Economic Literature 40(2): 351-401.

Gillingham, K., M. Harding, and D. Rapson. 2012. Split Incentives and Household Energy Consumption. Energy Journal 33(2): 37-62.

Gillingham, K., R.G. Newell, and K. Palmer. 2006. Energy Efficiency Policies: A Retrospective Examination. Annual Review of Environment and Resources 31: 161-92.

Gillingham, K., R.G. Newell, and K. Palmer. 2009. Energy Efficiency Economics and Policy. Annual Review of Resource Economics 1: 597-620.

Gillingham, K., and K. Palmer. 2013. Bridging the Energy Efficiency Gap: Insights for Policy from Theory and Empirical Analysis. Discussion paper 13-02. Washington, DC: Resources for the Future.

Green, Leonard, Joel Myerson, and Edward McFadden. 1997. Rate of Temporal Discounting Decreases with Amount of Reward. Memory \& Cognition 25(5): 715-23.

Gromet, D.M., H. Kunreuther, and R.P. Larrick. 2013. Political Ideology Affects EnergyEfficiency Attitudes and Choices. Proceedings of the National Academy of Sciences. Published online ahead of print April 29, 2013, doi:10.1073/pnas.1218453110.

Harrison, Glenn W., Morten I. Lau, and Melonie B. Williams. 2002. Estimating Individual Discount Rates in Denmark: A Field Experiment. The American Economic Review 92(5): $1606-17$.

Hausman, Jerry A. 1979. Individual Discount Rates and the Purchase and Utilization of EnergyUsing Durables. Bell Journal of Economics 10: 33-54.

Houde, S. 2011. How Consumers Respond to Product Certification: A Welfare Analysis of the Energy Star Program. Unpublished manuscript. Stanford, CA: Stanford University.

Jaffe, Adam B., and Robert N. Stavins. 1994. The Energy Paradox and the Diffusion of Conservation Technology. Resource and Energy Economics 16: 91-122.

Kessels, R., P. Goos, and M. Vandebroek. 2006. A Comparison of Criteria To Design Efficient Choice Experiments. Journal of Marketing Research 43: 409-19.

Kessels, R., B. Jones, P. Goos, and M. Vandebroek. 2009. An Efficient Algorithm For Constructing Bayesian Optimal Choice Designs. Journal of Business and Economic Statistics 27: 279-91.

Larrick, R., and J. Soll. 2008. The MPG Illusion. Science 320(5883): 1593-4.

Loewenstein, G. 1987. Anticipation and the Valuation of Delayed Consumption. Econ. J. 97: 666-84.

Louviere, J.J., D.A. Hensher, and J.D. Swait. 2000. Stated Choice Methods: Analysis and Applications. Cambridge, UK: Cambridge University Press.

McFadden, D.L. 1974. Conditional Logit Analysis of Qualitative Choice Behavior. In Frontiers in Econometrics, edited by P. Zarembka. New York: Academic Press, 105-142..

McFadden, D.L. 1984. Econometric Analysis of Qualitative Response Models. In Handbook of 
Econometrics, edited by Z. Griliches and M. Intrilligator. Amsterdam: Elsevier, 13961456.

McFadden, D., and K. Train. 2000. Mixed MNL Models for Discrete Response. Journal of Applied Econometrics 15: 447-70.

Metcalf, G.E. 1994. Economics and Rational Conservation Policy. Energy Policy 22: 819-25

Morgenstern, R.D., and S. Al-Jurf. 1999. Can Free Information Really Accelerate Technology Diffusion? Technological Forecasting and Social Change 61: 13-24.

Newell, R.G., A.B. Jaffe, and R.N. Stavins. 1999. The Induced Innovation Hypothesis and Energy-Saving Technological Change. Quarterly Journal of Economics 114(3): 941-75.

Rabin, M., and G. Weizsacker. 2009. Narrow bracketing and dominated choices. The American Economic Review 99 (4): 150831543(36).

Ruderman H., M. Levine, and J. McMahon. 1987. The Behavior of the Market for Energy Efficiency in Residential Appliances Including Heating and Cooling Equipment. The Energy Journal 8: 101-24.

Sallee, J. 2012. Rational Inattention and Energy Efficiency. Unpublished manuscript. Chicago: University of Chicago; Cambridge, MA: National Bureau of Economic Research.

Sandor, Z., and M. Wedel. 2002. Profile Construction in Experimental Designs for Mixed Logit Models. Marketing Science 21: 455-75.

Sutherland, R.J. 1991. Market Barriers to Energy Efficiency Investments. The Energy Journal 12: $15-34$.

Thaler, Richard H. 1981. Some Empirical Evidence on Dynamic Inconsistency. Econ. Letters 8: 201-7.

Tietenberg, Tom. 2009. Reflections_Energy Efficiency Policy: Pipe Dream or Pipeline to the Future? Review of Environmental Economics and Policy 3(2): 304-20.

Train, K. 1985. Discount Rates in Consumers' Energy-Related Decisions: A Review of the Literature. Energy 10: 1243-53.

Train, K. 2003. Discrete Choice Methods with Simulation. Cambridge, UK: Cambridge University Press.

Train, K., and M. Weeks. 2005. Discrete Choice Models in Preference Space and Willingness-toPay Space. In Applications of Simulation Methods in Environmental and Resource Economics, edited by R. Scarpa and A. Alberini. Dordrecht, the Netherlands: Springer, $1-16$.

Turrentine, T., and K. Kurani. 2007. Car Buyers and Fuel Economy. Energy Policy 35(2): 121323.

US Census Bureau. 2012. American Housing Survey for the United States: 2011. Series H-150, National Summary Data. http://www.census.gov/housing/ahs/data/national.html (accessed June 12, 2013). 
Wahlund, R., and J. Gunnarsson. 1996. Mental Discounting and Financial Strategies. J. Econ. Psych. 17(6): 709-30. 


\section{Appendix}

Table A1. Water Heater-Range of Potential Attribute Levels

\begin{tabular}{|c|c|c|c|c|c|c|c|c|}
\hline \multirow[b]{2}{*}{ Fuel type } & \multicolumn{2}{|c|}{ Energy cost (\$) } & \multicolumn{2}{|c|}{ Price (\$) } & \multicolumn{2}{|c|}{$\mathrm{CO}_{2}$ emissions (lbs) } & \multicolumn{2}{|c|}{$\begin{array}{c}\mathrm{CO}_{2} \text { emissions (miles } \\
\text { equivalent) }\end{array}$} \\
\hline & Low & High & Low & High & Low & High & Low & High \\
\hline Natural gas & 196 & 380 & 320 & 1,420 & 2,164 & 4,195 & 2,342 & 4,541 \\
\hline Propane & 329 & 640 & 320 & 1,420 & 2,164 & 4,195 & 2,342 & 4,541 \\
\hline Electric & 353 & 577 & 249 & 1,599 & 3,630 & 7,065 & 3,929 & 7,648 \\
\hline
\end{tabular}

Table A2. Credit Amounts in the Elicitation of Individual-Specific Discount Rates

\begin{tabular}{cccc}
\hline Credit A & & Credit B & $\begin{array}{c}\text { Discount rate for which the } \\
\text { present value of } \\
\text { credits A and B are equal }\end{array}$ \\
\hline$\$ 1,000$ & vs. & $\$ 1,019$ & $2 \%$ \\
$\$ 1,000$ & vs. & $\$ 1,037$ & $4 \%$ \\
$\$ 1,000$ & vs. & $\$ 1,057$ & $6 \%$ \\
$\$ 1,000$ & vs. & $\$ 1,076$ & $8 \%$ \\
$\$ 1,000$ & vs. & $\$ 1,096$ & $10 \%$ \\
$\$ 1,000$ & vs. & $\$ 1,116$ & $12 \%$ \\
$\$ 1,000$ & vs. & $\$ 1,137$ & $14 \%$ \\
$\$ 1,000$ & vs. & $\$ 1,158$ & $16 \%$ \\
$\$ 1,000$ & vs. & $\$ 1,179$ & $18 \%$ \\
$\$ 1,000$ & vs. & $\$ 1,201$ & $20 \%$ \\
$\$ 1,000$ & vs. & $\$ 1,258$ & $25 \%$ \\
$\$ 1,000$ & vs. & $\$ 1,317$ & $30 \%$ \\
$\$ 1,000$ & vs. & $\$ 1,443$ & $40 \%$ \\
$\$ 1,000$ & vs. & $\$ 1,581$ & $50 \%$ \\
$\$ 1,000$ & vs. & $\$ 1,733$ & $60 \%$ \\
$\$ 1,000$ & vs. & $\$ 1,989$ & $75 \%$ \\
$\$ 1,000$ & vs. & $\$ 2,501$ & $100 \%$ \\
\hline
\end{tabular}


Table A3. Estimation Results Using Individual-Specific Discount Rates, Fixed-Parameter Model

\begin{tabular}{|c|c|c|c|c|c|}
\hline Variable & $\begin{array}{c}\text { Units of } \\
\text { coefficient }\end{array}$ & $\begin{array}{c}\text { Coefficient } \\
\text { estimate }\end{array}$ & $\begin{array}{l}\text { Std. } \\
\text { error }\end{array}$ & $t$-stat & $\begin{array}{c}p- \\
\text { value }\end{array}$ \\
\hline Purchase price $(\$)$ & $\begin{array}{l}\text { utils per } \$ \\
\text { WTP }\end{array}$ & -24.33 & 0.59 & -41.29 & 0.00 \\
\hline \multicolumn{6}{|c|}{ Information attribute indicator $(0 / 1)$ interactions with discounted operating cost (\$) } \\
\hline Any operating cost info. & \multirow{7}{*}{$\begin{array}{l}\text { \$ WTP per \$ } \\
\text { saved in } \\
\text { discounted } \\
\text { operating } \\
\text { cost }\end{array}$} & 0.689 & 0.053 & 12.911 & 0.000 \\
\hline Operating cost relative to range & & 0.109 & 0.069 & 1.581 & 0.114 \\
\hline EnergyGuide image & & -0.120 & 0.048 & -2.505 & 0.012 \\
\hline Energy Star logo & & -0.165 & 0.070 & -2.350 & 0.019 \\
\hline Physical energy info. & & 0.308 & 0.074 & 4.141 & 0.000 \\
\hline $\mathrm{CO}_{2}$ emissions info. & & 0.237 & 0.060 & 3.949 & 0.000 \\
\hline Relative grade info. (EU-style) & & 0.587 & 0.085 & 6.939 & 0.000 \\
\hline $\mathrm{CO}_{2}$ emissions (tons per year) & $\begin{array}{c}\text { \$ WTP per } \\
\text { ton saved per } \\
\text { year }\end{array}$ & 119.3 & 22.1 & 5.409 & 0.00 \\
\hline Electricity usage (kWh per year) & $\begin{array}{l}\text { \$WTP per } \\
\text { kWh saved } \\
\text { per year }\end{array}$ & 0.697 & 0.060 & 11.54 & 0.00 \\
\hline $\begin{array}{l}\text { Natural gas usage (therms per } \\
\text { year) }\end{array}$ & $\begin{array}{l}\$ \text { WTP per } \\
\mathrm{kWh} \text { saved } \\
\text { per year }\end{array}$ & 7.834 & 0.701 & 11.18 & 0.00 \\
\hline Energy Star logo w/ other info. & \$ WTP & 638.0 & 53.4 & 11.94 & 0.00 \\
\hline Energy Star logo alone & \$ WTP & 683.7 & 41.3 & 16.56 & 0.00 \\
\hline
\end{tabular}

Notes: Number of observations equals 1,214. Coefficients are estimated relative to the coefficient on purchase price, yielding coefficient estimates expressed in \$ WTP per unit. 
Table A4. Estimation Results Using Constant 5 Percent Discount Rate, Fixed-Parameter Model

\begin{tabular}{|c|c|c|c|c|c|}
\hline Variable & $\begin{array}{c}\text { Units of } \\
\text { coefficient }\end{array}$ & $\begin{array}{c}\text { Coefficient } \\
\text { estimate }\end{array}$ & Std error & $t$-stat & $p$-value \\
\hline $\begin{array}{l}\text { Purchase price } \\
(\$)\end{array}$ & $\begin{array}{c}\text { utils per } \$ \\
\text { WTP }\end{array}$ & -25.42 & 0.620 & -41.03 & 0 \\
\hline \multicolumn{6}{|c|}{ Information attribute indicator $(0 / 1)$ interactions with discounted operating costs $(\$)$} \\
\hline $\begin{array}{l}\text { Any operating } \\
\text { cost info. }\end{array}$ & \multirow{7}{*}{$\begin{array}{c}\text { \$ WTP per } \\
\text { \$ saved in } \\
\text { discounted } \\
\text { operating } \\
\text { costs }\end{array}$} & 0.531 & 0.039 & 13.54 & 0.000 \\
\hline $\begin{array}{l}\text { Operating cost } \\
\text { relative to range }\end{array}$ & & -0.033 & 0.048 & -0.69 & 0.490 \\
\hline $\begin{array}{l}\text { EnergyGuide } \\
\text { image }\end{array}$ & & -0.007 & 0.032 & -0.23 & 0.819 \\
\hline Energy Star logo & & -0.144 & 0.056 & -2.56 & 0.011 \\
\hline $\begin{array}{l}\text { Physical energy } \\
\text { info. }\end{array}$ & & 0.189 & 0.049 & 3.83 & 0.000 \\
\hline $\begin{array}{l}\mathrm{CO}_{2} \text { emissions } \\
\text { info. }\end{array}$ & & 0.159 & 0.039 & 4.08 & 0.000 \\
\hline $\begin{array}{l}\text { Relative grade } \\
\text { info. (EU-style) }\end{array}$ & & 0.381 & 0.059 & 6.50 & 0.000 \\
\hline $\begin{array}{l}\mathrm{CO}_{2} \text { emissions } \\
\text { (tons per year) }\end{array}$ & $\begin{array}{c}\text { \$ WTP per } \\
\text { ton saved } \\
\text { per year }\end{array}$ & 102.3 & 22.3 & 4.59 & 0.000 \\
\hline $\begin{array}{l}\text { Electricity usage } \\
\text { (kWh per year) }\end{array}$ & $\begin{array}{l}\text { \$WTP per } \\
\text { kWh saved } \\
\text { per year }\end{array}$ & 0.693 & 0.058 & 11.92 & 0.000 \\
\hline $\begin{array}{l}\text { Natural gas } \\
\text { usage (therms } \\
\text { per year) }\end{array}$ & $\begin{array}{l}\text { \$WTP per } \\
\text { kWh saved } \\
\text { per year }\end{array}$ & 7.841 & 0.674 & 11.63 & 0.000 \\
\hline $\begin{array}{l}\text { Energy Star logo } \\
\text { w/ other info. }\end{array}$ & \$ WTP & 665.1 & -62.26 & 10.68 & 0.000 \\
\hline $\begin{array}{l}\text { Energy Star logo } \\
\text { alone }\end{array}$ & \$ WTP & 678.0 & -39.69 & 17.08 & 0.000 \\
\hline
\end{tabular}

Notes: Number of observations equals 1,214. Coefficients are estimated relative to the coefficient on purchase price, yielding coefficient estimates expressed in \$ WTP per unit. 
Table A5. Information Attributes Present in Each Labeling Treatment

\begin{tabular}{|l|c|c|c|c|c|c|c|c|c|c|c|c|}
\hline \multirow{2}{*}{ Information attribute } & \multicolumn{10}{|c|}{ Treatment number } \\
\cline { 2 - 12 } & $\mathrm{1}$ & 2 & 3 & 4 & 5 & 6 & 7 & 8 & 9 & 10 & 11 & 12 \\
\hline Operating cost & $\mathrm{x}$ & $\mathrm{x}$ & & $\mathrm{x}$ & $\mathrm{x}$ & $\mathrm{x}$ & $\mathrm{x}$ & & $\mathrm{x}$ & $\mathrm{x}$ & & $\mathrm{x}$ \\
\hline Operating cost relative to range & $\mathrm{x}$ & $\mathrm{x}$ & & $\mathrm{x}$ & & $\mathrm{x}$ & $\mathrm{x}$ & & $\mathrm{x}$ & $\mathrm{x}$ & & \\
\hline EnergyGuide image & $\mathrm{x}$ & $\mathrm{x}$ & $\mathrm{x}$ & & & & & & $\mathrm{x}$ & & & \\
\hline Physical energy & $\mathrm{x}$ & & $\mathrm{x}$ & & & & & & & & & \\
\hline Energy Star logo & & & & & & $\mathrm{x}$ & $\mathrm{x}$ & $\mathrm{x}$ & & & & \\
\hline $\mathrm{CO}_{2}$ emissions & & & & & & & & & $\mathrm{x}$ & $\mathrm{x}$ & $\mathrm{x}$ & \\
\hline Relative grade (EU-style) & & & & & & & & & & & & $\mathrm{x}$ \\
\hline
\end{tabular}


Figure A1. Examples of Different Labeling Treatments Included in the Experiment

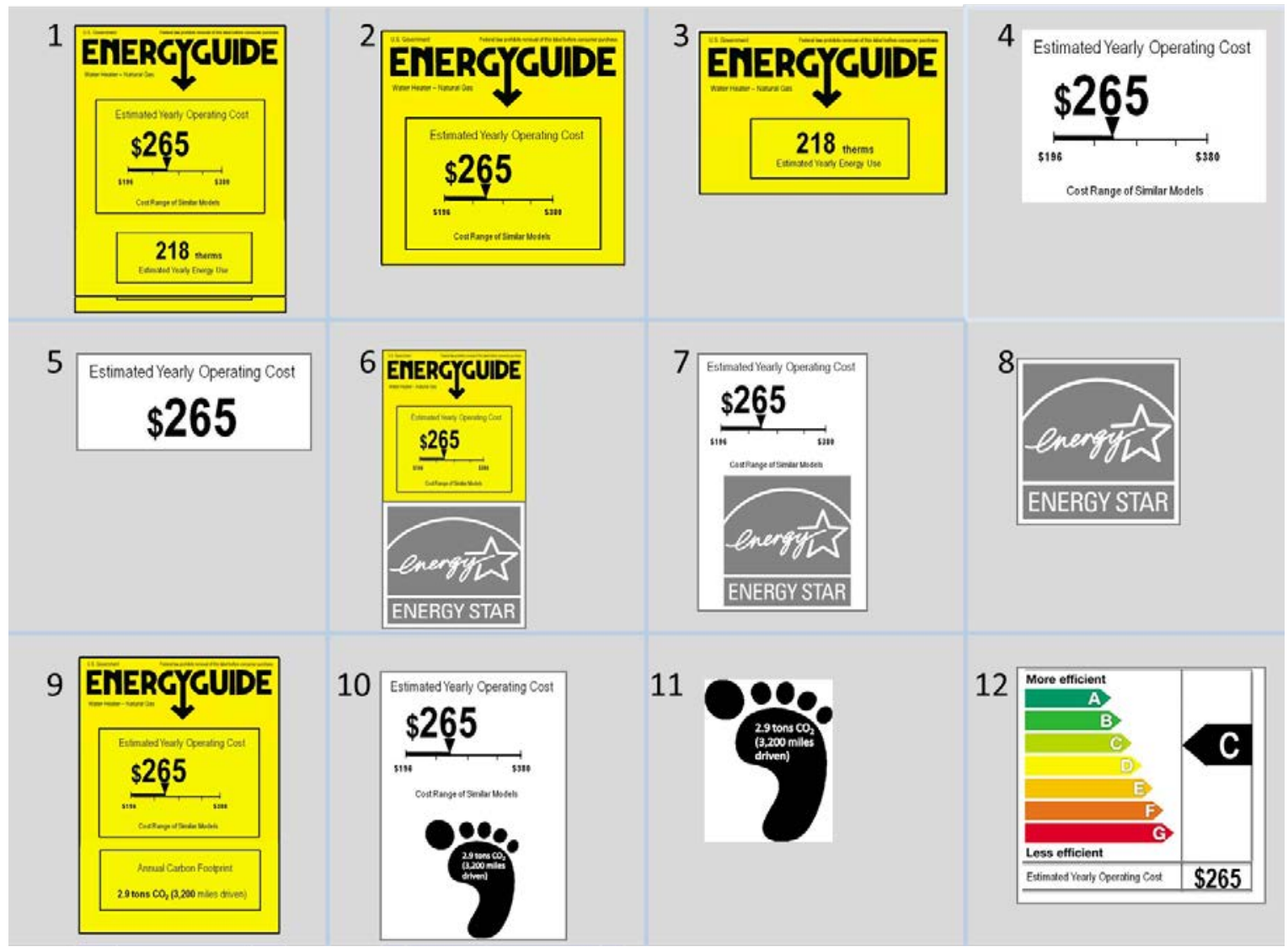




\title{
Figure A2. Description of the Energy Label and Different Attributes in the Survey, Current EnergyGuide Label Treatment
}

\author{
Choosing a Central Water Heater
}

Next several questions ask you to choose from different water heater alternatives for your home. The survey asks you to choose multiple times from three different water heater options as if those options were the only ones available when you are making the replacement purchase. The available water heater options differ only in:

- Purchase Price

- Energy Use $\longleftarrow$ The range of Purchase Price and Energy Use in this survey corresponds to the actual water heater models currently in the market.

Purchase Price denotes your out-of-pocket cost of purchasing the appliance, after all possible rebates, credits, and other deductions. In other words, ignore any energy and other rebates, credits, and other deductions when making the choice.

Energy Use is described using the EnergyGuide label administered by the Federal Trade Commission, the nation's consumer protection agency. EnergyGuide label can help you compare the energy use of different models as you shop for an appliance. The more energy efficient an appliance is, the less it costs to run, and the lower your utility bills. The example below explains information in the EnergyGuide.

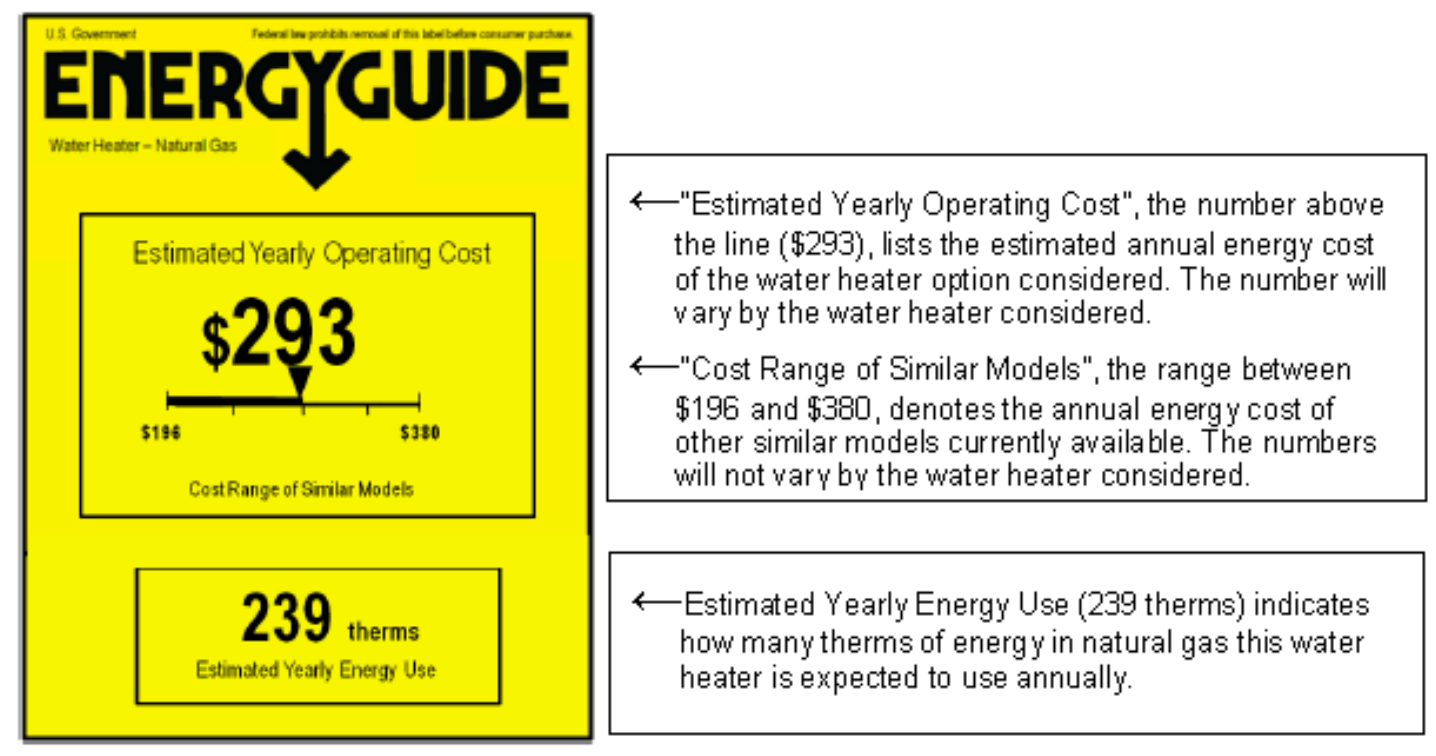

Besides these attributes, consider the different water heater options shown in each question exactly similar. They meet your general requirements, perform equally well, are expected to last equally long, take up the same space in your house, cost the same to install, and are the same in all other respects. 